ARTICLE

https://doi.org/10.1038/s41467-019-10350-6

\title{
SAGA DUBm-mediated surveillance regulates prompt export of stress-inducible transcripts for proteostasis
}

Minhoo Kim ${ }^{1}$, Yoonjung Choi ${ }^{1}$, Harim Kim (i) ${ }^{1} \&$ Daeyoup Lee ${ }^{1}$

During stress, prompt export of stress-inducible transcripts is critical for cell survival. Here, we characterize a function of the SAGA (Spt-Ada-Gcn5 acetyltransferase) deubiquitylating module (DUBm) in monitoring messenger ribonucleoprotein (mRNP) biogenesis to regulate non-canonical mRNA export of stress-inducible transcripts. Our genetic and biochemical analyses suggest that there is a functional relationship between Sgf73p of DUBm and the essential mRNA export factor, Yra1p. Under physiological conditions, Sgf73p is critical for the proper chromatin localization and RNA binding of Yra1p, while also quality controlling the biogenesis of mRNPs in conjunction with the nuclear exosome exonuclease, Rrp6p. Under environmental stress, when immediate transport of stress-inducible transcripts is imperative, Sgf73p facilitates the bypass of canonical surveillance and promotes the timely export of necessary transcripts. Overall, our results show that the Sgf73p-mediated plasticity of gene expression is important for the ability of cells to tolerate stress and regulate proteostasis to survive under environmental uncertainty.

\footnotetext{
${ }^{1}$ Department of Biological Sciences, Korea Advanced Institute of Science and Technology, Daejeon 34141, South Korea. Correspondence and requests for materials should be addressed to D.L. (email: daeyoup@kaist.ac.kr)
} 
$\mathrm{n}$ the eukaryotic cell, the genetic information is compartmentalized into a structure called the nucleus, enabling the temporal and spatial regulation of gene expression. Gene expression involves various steps, ranging from transcriptional activation, elongation, and RNA processing in the nucleus, to the transport of export-competent mRNAs to the cytoplasm for translation. During the tightly coordinated process of mRNA export, various factors are recruited to the transcription site and nascent RNA. The TRanscription and EXport (TREX) complex consists of the THO complex and Yralp/Sub2p, which are involved in transcription elongation and mRNA export, respectively ${ }^{1,2}$. Yralp is responsible for recruiting the Mex67pMtr2p complex, which binds to the newly synthesized mRNA and escorts it to the nuclear pore complex (NPC) ${ }^{3,4}$. Finally, a physical interaction between Mex67p and the TREX-2-NPC complex facilitates the export of properly assembled messenger ribonucleoproteins (mRNPs) to the cytoplasm ${ }^{5,6}$.

Under physiological conditions, surveillance systems strictly ensure that only export-competent mRNPs are transported. In yeast, mRNP quality control is monitored by Rrp6p, the exonuclease of the nuclear exosome complex ${ }^{7,8}$. Studies have shown that Rrp6p is required for the nuclear retention of aberrant mRNPs in $3^{\prime}$-end processing-defective mutants ${ }^{8,9}$. In contrast, upon environmental stress, the canonical mRNA export process is bypassed and immediate export of stress-related transcripts is undertaken to maintain proteostasis and maximize cell survival.

We previously reported that a physical interaction between the proteasomal 19S regulatory particle (RP) and the SAGA complex (a highly conserved transcriptional co-activator) is important for mRNA export in Saccharomyces cerevisiae ${ }^{10}$. The proteasome-SAGA interaction causes a functional Sgf73DUBm (deubiquitylating module) subcomplex to separate from SAGA. The rpt2-1 mutant, which shows perturbation of the proteasome-SAGA interaction, also exhibits significant retention of Sgf73-DUBm near promoter regions, along with defects in mRNA export.

In the present work, we characterize a functional relationship between Sgf73p of the DUBm and the essential mRNA export factor, Yralp. Under normal conditions, Sgf73p directly interacts with Yralp and is important for its proper chromatin localization and transcript binding. Here, we demonstrate that Sgf73p plays a central role in the surveillance of mRNP biogenesis through a concerted action with Rrp6p. During environmental stress, when prompt export of stress-related transcripts is required, Sgf73p promotes a bypass of the canonical mRNA export surveillance and allows immediate export of specific transcripts, including those of molecular chaperone genes. This facilitates cellular proteostasis by acting to unfold protein aggregates in the cytoplasm. Our results collectively show that, in response to a stressful environmental change, Sgf73p orchestrates the selective export of immediate genes by occupying their upstream-activating sequences (UASs), and is thus crucial to sustaining cell adaptability.

\section{Results}

sgf73 $\Delta$ restores the growth defects of mRNA export mutants. To investigate how the retention of Sgf73p affects mRNA export, we assessed whether there was a genetic interaction between SGF73 and YRA1. The essential mRNA export factor, Yralp, is recruited as part of the TREX complex and mediates the association of the Mex67p-Mtr2p complex with nascent transcripts $1,2,11$. Surprisingly, at a non-permissive temperature $\left(37^{\circ} \mathrm{C}\right)$, SGF73 deletion partially restored the growth defect seen in the yra 1-1 mutant ${ }^{11}$ (Fig. 1a, upper panel), whereas deletion of two other subunits of the Sgf73-DUBm, UBP8, or SGF11, did not
(Fig. 1a, middle panel). The deletion of SUS1, which is another subunit of Sgf73-DUBm, was reportedly associated with synthetic lethality when combined with yra1-1, possibly indicating that Sus1p plays a critical role in mRNA export as a component of the TREX-2 complex ${ }^{12}$. Removal of Gcn5p, the acetyltransferase of SAGA, did not affect the growth defect of yra1-1, but deletion of SPT20, which causes disintegration of the entire SAGA complex, partially restored yra1-1 cell growth (Fig. 1a, lower panel). To test whether the observed genetic interaction was restricted to the yra1-1 mutant, we combined SGF73 deletion with a number of well-characterized mRNA export-defective mutants, including mex67-5, mtr2-9, sub2-85, and npl3 $\Delta$ (Supplementary Fig. 1a-d). Indeed, the loss of SGF73 partially restored cell growth in all tested mRNA export-defective mutants. These results indicate that deletion of SGF73 improves the overall fitness of cells growing in a mRNA export-defective environment. Interestingly, SGF73 did not rescue the growth defect of nab2-34, another mRNA export-defective mutant. Npl3p and Nab2p were reported to function as independent adapters of the mRNA export factor, Mex67p, suggesting that Sgf73p and Nab2p play distinct roles ${ }^{13}$.

To further confirm the positive genetic interaction between SGF73 and YRA1, we used the galactose-inducible promoter, $P_{\mathrm{GAL}}$, to overexpress Sgf73p in certain mutants (Fig. $1 \mathrm{~b}$ and Supplementary Fig. 1f). We observed notable suppression of the rescue phenotype in the yra1-1 sgf73 mutant at the restrictive temperature upon Sgf73p overexpression (Fig. 1b, lower panel, YPG), while a lesser extent of rescue was seen at the permissive temperature $\left(30^{\circ} \mathrm{C}\right)$ (Fig. 1b, upper panel, YPG). Interestingly, overexpression of Sgf73p inhibited the growth of even yra1-1mutant cells incubated at the permissive temperature.

To assess potential differences in the gene expression patterns of the SGF73 deletion mutant compared to wildtype, we generated and analyzed mRNA-seq data. As shown in Supplementary Fig. 2, we did not observe any significant change in transcription for the sgf $73 \Delta$ mutant. Overall, our findings show that Sgf73p has a function in mRNA export that is independent of its function in transcriptional regulation.

Yralp is a bona fide binding partner of Sgf73p. Given the positive genetic interaction between SGF73 and YRA1, we speculated that these factors may physically interact. Indeed, our in vitro GST-protein pulldown assays indicated that both gelfiltration-purified Sgf73-DUBm (Fig. 1c) and recombinant Sgf73p (Fig. 1d) physically interacted with Yralp. Interestingly, the Sgf73-DUBm subunit, Suslp, was not recovered in the immunoprecipitated fraction (Fig. 1c, middle panel), suggesting that Sus1p has a different fate after Yralp binding. Sus1p is a subunit of the TREX-2 complex, whose interaction with the NPC is essential for proper mRNA export ${ }^{14}$; indeed, Sgf73p has been shown to be important for proper assembly of the TREX-2 complex ${ }^{15}$.

Yralp is composed of an RNA-recognition motif (RRM), two highly conserved N-terminal and C-terminal RNA export factorbinding protein (REF) domains, and two moderately conserved regions that flank the RRM, called the $\mathrm{N}$-variable and $\mathrm{C}$-variable domains ${ }^{3,11}$. To further define the region(s) within Yralp responsible for the physical interaction with $S g f 73 p$, we generated subfragments of Yralp using previously published GST-Yralp constructs $^{16}$ (Supplementary Fig. 3a). We found that Sgf73p bound to the $\mathrm{N}$-terminal and C-terminal regions of Yralp, but not the RRM (Fig. 1e). Surprisingly, Pcf11p, a component of the cleavage and polyadenylation complex, was previously reported to bind the same domain within Yralp ${ }^{16,17}$.

To confirm the physical interaction between Sgf73p and Yralp in vivo, we performed co-immunoprecipitation (co-IP) assays. 
a

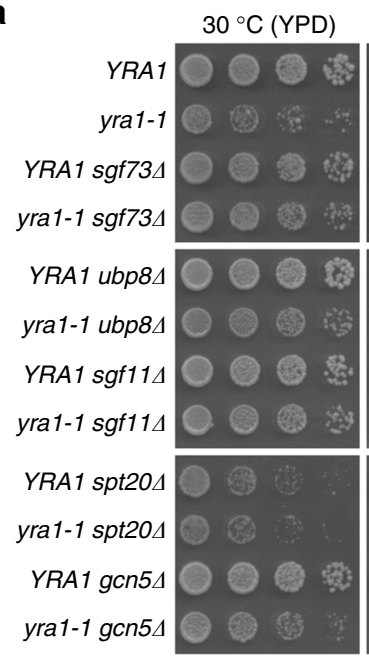

C

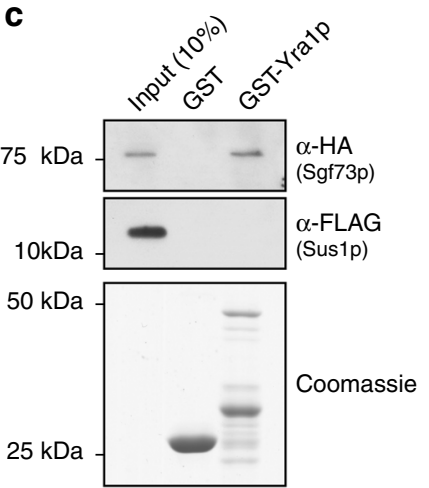

$\mathbf{f}$

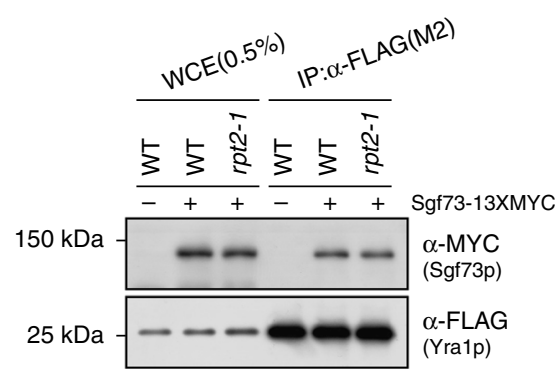

b

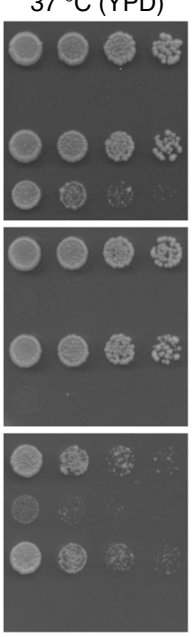

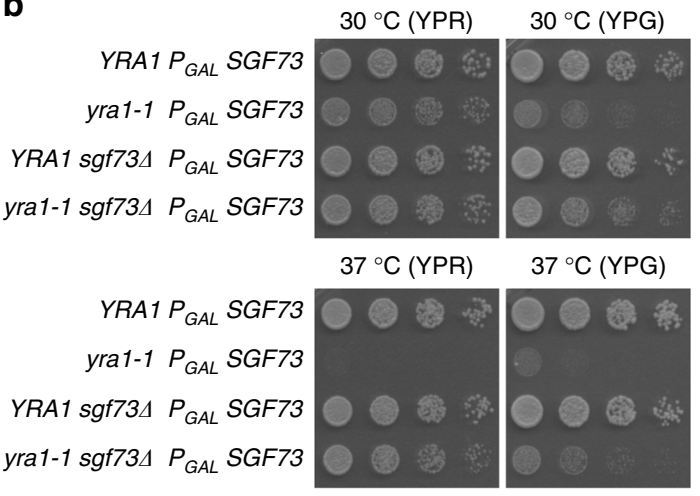

d

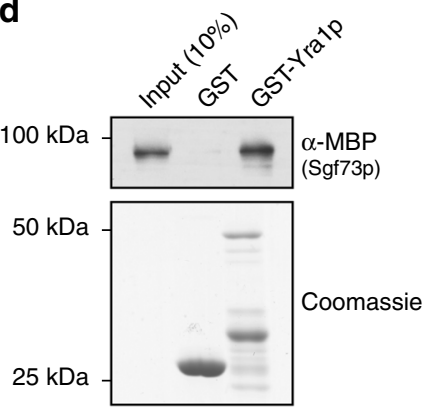

e

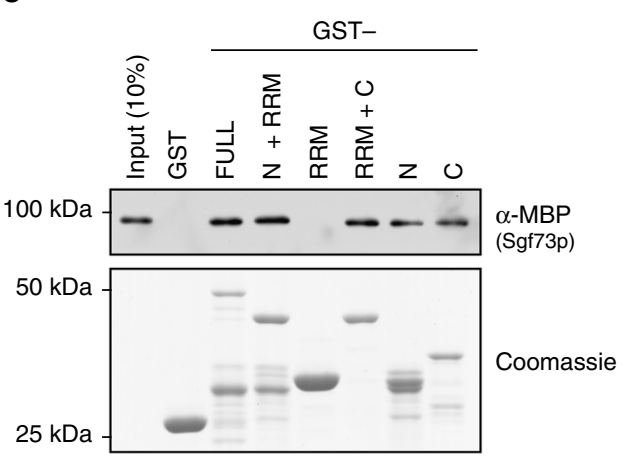

h

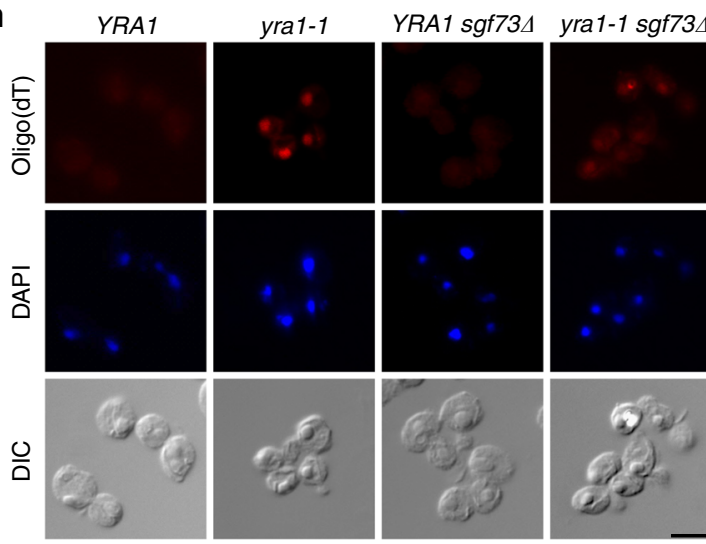

g

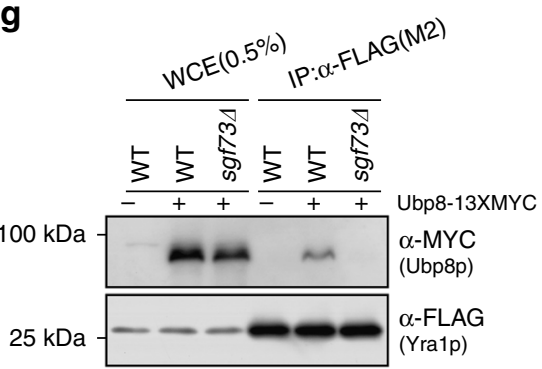

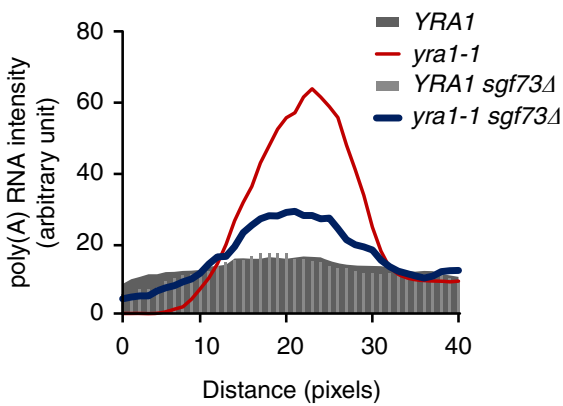

Yralp in wildtype cells but not in $s g f 73 \Delta$ mutant cells, supporting the direct interaction between Sgf73p and Yralp (Fig. 1g). Adalp and Spt20p, which are two additional subunits of the SAGA complex, interacted with Yralp in wildtype cells, but this association was significantly reduced in sgf73 cells
Yralp showed binding with Sgf73p in both wildtype and rpt2-1 cells (Fig. 1f). As the separation of the Sgf73-DUBm is inhibited in the rpt2-1 mutant, the binding of Yralp with Sgf73p in the mutant indicates that such binding occurs when Sgf73p is intact within the whole SAGA complex. Ubp8p showed binding with 
Fig. 1 Functional relationship between Sgf73p and Yra1p. a Spotting assays to assess genetic interactions between yra1-1 and SAGA subunit-deletion mutants. Cells were spotted onto YPD plates with five-fold serial dilutions and incubated at 30 and $37^{\circ} \mathrm{C}$. $\mathbf{b}$ Spotting assays to assess the effects of Sgf $73 p$ overexpression in the yra1-1 mutant. Cells transformed with $P_{G A L}$ SGF73 inserted into the URA3 locus were cultured in YP $+2 \%$ raffinose (YPR) medium and plated on YPR and YPG (YP $+2 \%$ galactose) media. Plates were incubated at 30 and $37^{\circ} \mathrm{C}$. c In vitro pulldown assay of gel-filtration-purified Sgf73-DUBm against GST-tagged Yra1p. Binding was assessed by Western blotting against Sgf73p ( $\alpha-H A)$ and Sus1p ( $\alpha$-FLAG). d In vitro pulldown assay of recombinant Sgf73p against GST-tagged Yra1p. Binding was assessed by Western blotting against Sgf73p ( $\alpha-M B P)$. e In vitro pulldown assays were performed using Sgf73p ( $\alpha$-MBP) and the indicated subfragments of Yralp ( $\alpha$-GST). f Co-immunoprecipitation (co-IP) assays of Sgf73p ( $\alpha-13 x M Y C)$ and Yra1p ( $\alpha-5 x F L A G)$ in wildtype and rpt2-1 cells. Yra1p ( $\alpha-5 x$ FLAG) was immobilized on anti-FLAG M2 affinity gel and co-IP was assessed by Western blotting. $\mathbf{g}$ Co-IP assay of Ubp8p ( $\alpha-13 \times$ MYC) and Yra1p ( $\alpha-5 x F L A G)$ in wildtype and sgf73 cells. Yra1p ( $\alpha-5 x F L A G)$ was immobilized on anti-FLAG M2 affinity gel and co-IP was

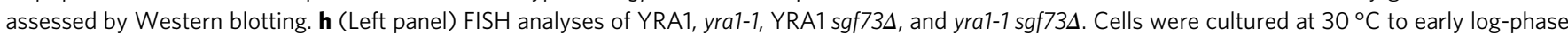
and shifted to $37^{\circ} \mathrm{C}$ for $2 \mathrm{~h}$. Poly-(A) + RNA was detected using Cy3-labeled oligo(dT) probes and DNA was counterstained with 4',6-diamidino-2phenylindole (DAPI). Scale bar, $5 \mu \mathrm{m}$. (Right panel) Quantification graph of poly-(A) + RNA intensity. Poly-(A) + RNA intensity was quantified using the same scan width of respective nuclei (determined by DAPI staining). WCE, whole-cell extract. Coomassie blue staining was used as a loading control

(Supplementary Fig. 3b, c). Yra1p has been demonstrated to be recruited to transcribed regions by the RNAPII C-terminal domain (CTD)-bound $3^{\prime}$-end processing factor, Pcf11 $\mathrm{p}^{16}$. However, Sgf73p did not show any physical interaction with Pcf11p in vivo (Supplementary Fig. 3d), and thus is unlikely to be involved in the initial recruitment of Yra1p. In contrast, Sub2p, whose binding with Yralp is reported to occur after chromatin recruitment of Yralp, showed binding in vivo (Supplementary Fig. 3e). From these findings, we hypothesize that Sgf73p interacts with Pcf11p-bound Yralp to enable subsequent processes of the mRNA export pathway.

To further assess the functional relationship between Sgf73p and Yralp in regulating mRNA export, we performed fluorescence in situ hybridization (FISH). As previously reported, a severe mRNA export defect was observed in the yra1-1 mutant at the non-permissive temperature $\left(37^{\circ} \mathrm{C}\right)$. Consistent with the findings from our genetic interaction assays, the mRNA export defects in yra1-1 cells were rescued by Sgf73p deletion (Fig. 1h). Taken together, these findings indicate that Sgf73p contributes to nuclear mRNA retention through Yralp.

Sgf73p acts as an RNA surveillance factor during mRNA export. The involvement of Sgf73p in the nuclear retention of mRNAs suggests that it may contribute to quality control during mRNP biogenesis. The nuclear exosome, Rrp6p, is reported to be the key factor in the surveillance of mRNP assembly and export ${ }^{8}$. Thus, we speculated that, as a quality control factor, Sgf73p is likely to display a functional relationship with Rrp6p. Interestingly, we found that Sgf73p deletion partially rescued the growth defect of the rrp6 $6 \Delta$ mutant at the restrictive temperature. Consistent with the genetic interactions observed between Yralp and the SAGA complex, the positive interaction with the rrp6 $\Delta$ mutant was restricted to $S G F 73$ within the DUBm (Fig. 2a). A rescue phenotype was also observed between the spt20 4 and rrp6 $\triangle$ mutants. A negative genetic interaction between RRP6 and SUS1 was previously observed through high-throughput analysis $^{18}$, and depletion of RRP6 was reported to yield synthetic lethality when combined with mRNA export mutants, including YRA $1^{19}$. Additionally, a physical interaction between Sgf73p and Rrp6p in vivo was confirmed by co-IP assays (Fig. 2b). To test whether they have a cooperative function, we assessed mRNA export defects in the respective mutants. We observed significant retention of transcripts in the $\operatorname{rrp} 6 \Delta$ mutant, and found that this nuclear retention of mRNAs was alleviated by the deletion of SGF73 (Fig. 2c).

The identified functional relationship between Sgf73p and Rrp6p prompted us to assess how Sgf73p deletion affects a 3 '-end processing-defective mutant. RRP6 deletion was reported to rescue the growth defects of $3^{\prime}$-end processing-defective mutants, including rna14- $3^{20}$. Similarly, we found that the growth of rna14-3 cells was restored by deletion of SGF73 (Fig. 2d).

Under normal conditions, only export-competent transcripts are stringently exported to the cytoplasm for further processes of gene expression; in mRNA export-defective or 3 '-end processingdefective mutants, there are severe growth defects due to nuclear retention of transcripts that are necessary for normal cellular functions. In the absence of a functional surveillance system, such as in the SGF73 or RRP6 deletion mutants, premature transcripts can bypass quality control and undergo nucleocytoplasmic transport. Supply of premature transcripts is reportedly less detrimental to cells than their complete absence ${ }^{21}$. Deletion of RRP6 was shown to improve the cell fitness of the $3^{\prime}$-end processing-defective mutant, rna14- $3^{22}$. Thus, despite the improvement in overall cell growth, we hypothesized that certain 3 '-end formation-defective phenotypes would be amplified in the absence of the surveillance factor, Sgf73p. To test this, we used a previously reported system in which changes in the amount of read-through transcripts produced from the HSP104 gene are measured in the rna14-3 mutant background ${ }^{23}$. We depleted cells of Rna14p using the anchor-away method (Rna14-AA) ${ }^{24}$. We detected significantly more read-through transcripts in Rna14AA cells exposed to rapamycin $(+R a p)$ compared to those treated with DMSO (Fig. 2e, left panel). Moreover, the amount of readthrough transcripts was significantly increased in the sgf $73 \Delta$ Rna14-AA mutant (Fig. 2e, right panel), suggesting that $3^{\prime}$-end processing defects are exacerbated by the deletion of SGF73.

Overall, our findings support a model in which the concerted actions of Sgf73p and Rrp6p ensure proper quality control of nuclear $\mathrm{mRNP}$ biogenesis.

Identification of the Sgf73p-regulated gene set. We previously reported a significant retention of Sgf73p-DUBm near promoter regions in the proteasome-SAGA interaction-defective mutant, $r p t 2-1^{10}$. To investigate the genes that are directly influenced by Sgf73p retention, we performed chromatin immunoprecipitation followed by high-throughput sequencing (ChIP-seq) against 5xFLAG-tagged Sgf73p. We confirmed the strong accumulation of Sgf73p in the rpt2-1 mutant near promoter regions of the representative genes used in our previous report (PMA1 and $P G K 1$ ), as well as those of other genes, including HSP104 and SSA1 (Fig. 3a). As shown in Fig. 3b, Sgf73-DUBm was retained near promoter regions throughout the genome in rpt2-1. To further confirm this localization, we performed ChIP-seq analysis against another subunit of the Sgf73-DUBm, Sgf11p. Indeed, Sgf11p showed co-localization with Sgf73p in rpt2-1 cells, whereas in the $s g f 73 \Delta$ mutant, which entirely lacks the DUBm in its SAGA complex, Sgf11p showed a substantial, if not complete, decrease in enrichment (Fig. 3a, b). 
a

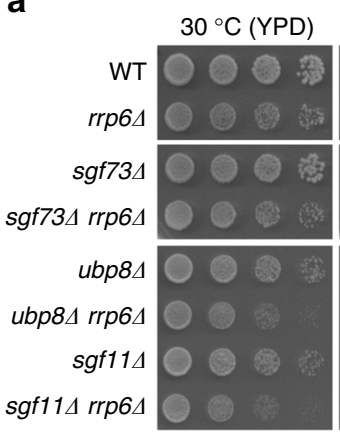

$37^{\circ} \mathrm{C}(\mathrm{YPD})$

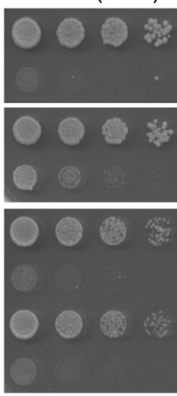

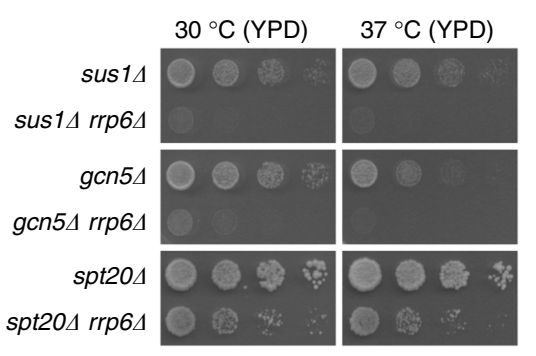

b

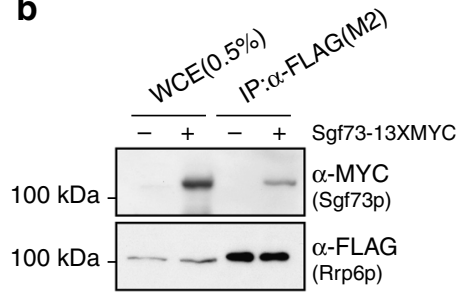

C

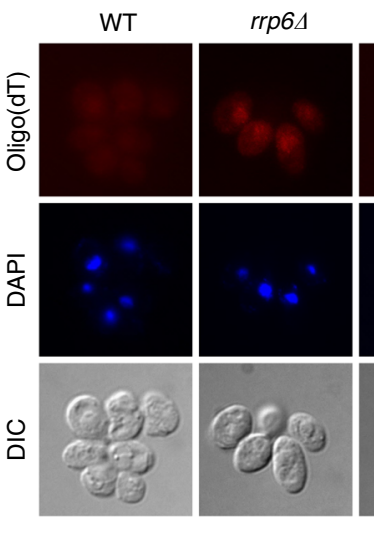

d
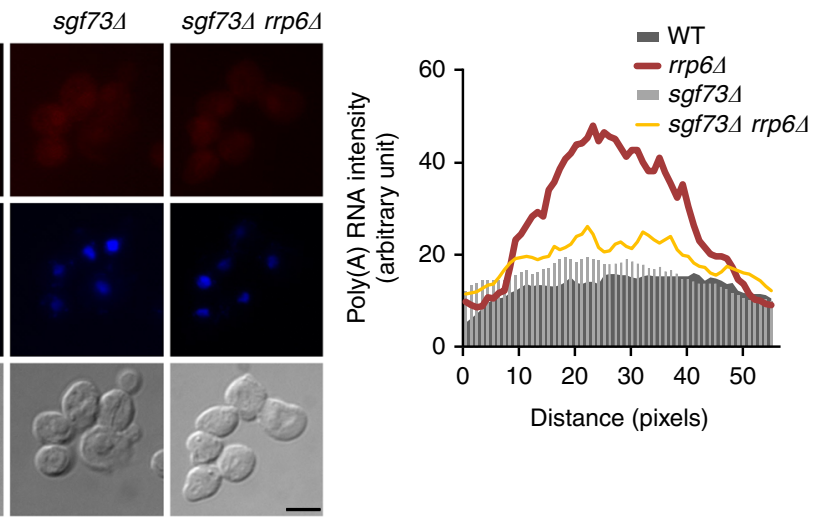

e
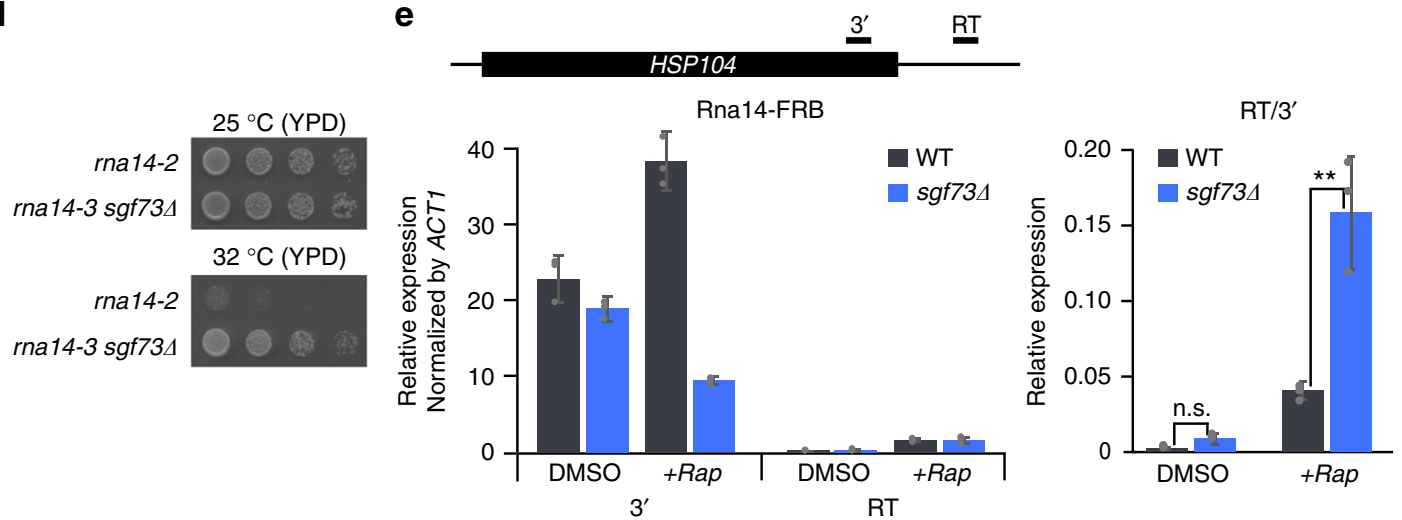

Fig. 2 Sgf73p functions in mRNP quality control. a Spotting assays to assess genetic interactions between rrp6 and SAGA subunit-deletion mutants. Cells were spotted onto YPD plates with five-fold serial dilutions and incubated at 30 and $37^{\circ} \mathrm{C}$. b Co-IP assay of Sgf73p ( $\left.\alpha-M Y C\right)$ and Rrp6p ( $\alpha$-FLAG). Rrp6p $(\alpha-5 \times F L A G)$ was immobilized on anti-FLAG M2 affinity gel and co-IP was assessed by Western blotting. c (Left panel) FISH analyses of wildtype, rrp64,

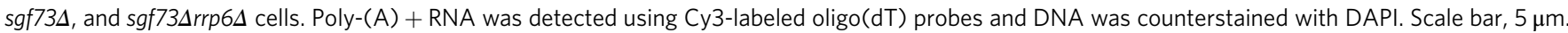
(Right panel) Quantification graph of poly-(A) + RNA intensity. Poly-(A) + RNA intensity was quantified using the same scan width of respective nuclei (determined by DAPI staining). d Spotting assays to assess the genetic interaction between rna14-3 and sgf73 4 . Cells were spotted onto YPD plates with five-fold serial dilutions and incubated at 25 and $32{ }^{\circ} \mathrm{C}$. e Quantification of read-through transcripts from the HSP104 gene in wildtype and sgf73A cells. Wildtype and sgf73 4 cells were depleted of Rna14p using the anchor-away method ( + Rap). Levels of read-through transcripts were normalized by $3^{\prime}-$ transcripts. Standard deviations of three independent experiments are shown by error bars and $P$-values were determined by Student's $t$-test $\left({ }^{\star} P \leq 0.05\right.$, ${ }^{* *} P \leq 0.01$, and $\left.{ }^{* \star *} P \leq 0.001\right)$. WCE, whole cell extract. RT, read-through

By using $\mathrm{HOMER}^{25}$ to perform peak-finding analysis, we identified and annotated genes with significant Sgf73-DUBm peaks $(n=690)$. Among the identified peaks, $84 \%(n=580)$ were found near promoter regions (Fig. 3c). For our further analyses, we focused on the genes that exhibited Sgf73-DUBm peaks near their promoter region, which we herein refer to as Sgf73-peak genes. To compare the localization of Sgf73-DUBm with that of SAGA, we utilized recently published ChEC-seq data for several SAGA subunits ${ }^{26}$. The ChEC-seq signals against Spt7p and Ubp8p showed enrichment in genes with Sgf73-DUBm peaks ( $n$ =580) (Supplementary Fig. 4a). We used HOMER to identify and annotate genes with Spt7p $(n=4366)$ and Ubp8p $(n=4770)$ peaks, and found that the Sgf73-peak genes showed significant overlaps with the Spt7-peak and Ubp8-peak genes $(P$-value $=1 \mathrm{e}$ -12) (Supplementary Fig. 4b).

To further characterize the Sgf73-DUBm peaks observed in the rpt2-1 mutant, we aligned Sgf73-DUBm enrichment with core promoters, marked by TFIIB (encoded by the SUA7 gene) occupancy. Interestingly, the Sgf73-DUBm peaks were enriched in regions upstream of core promoters (Fig. 3e, f). As UASs are reportedly located $60-300$ bp upstream of core promoters ${ }^{27}$, we speculate that Sgf73-DUBm is likely to be recruited to UASs as 
a

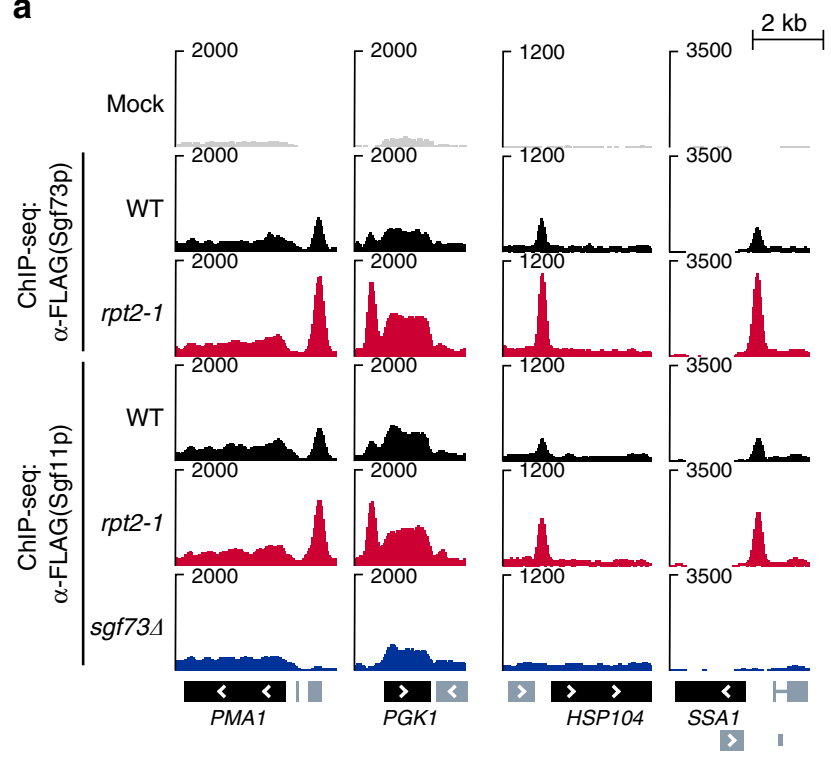

b

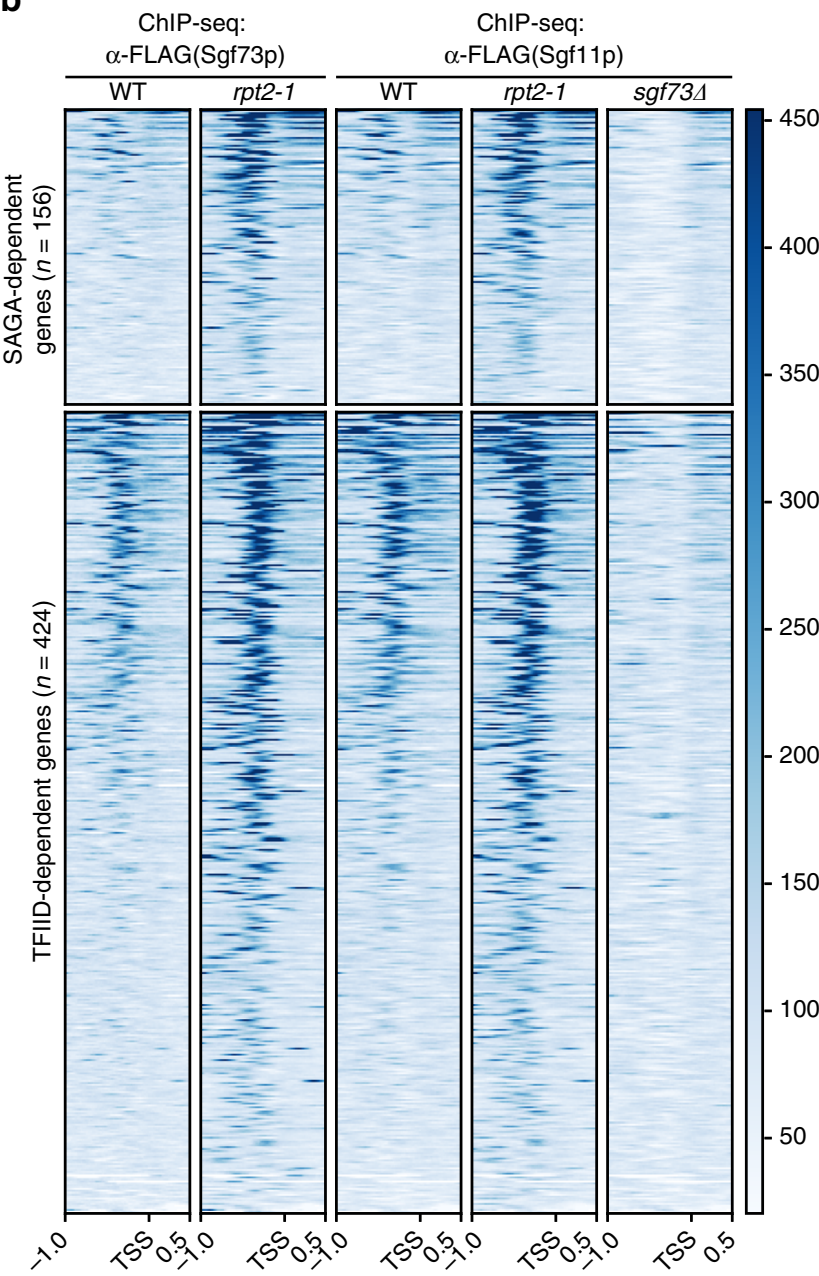

d

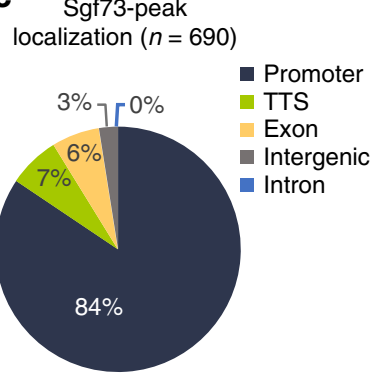

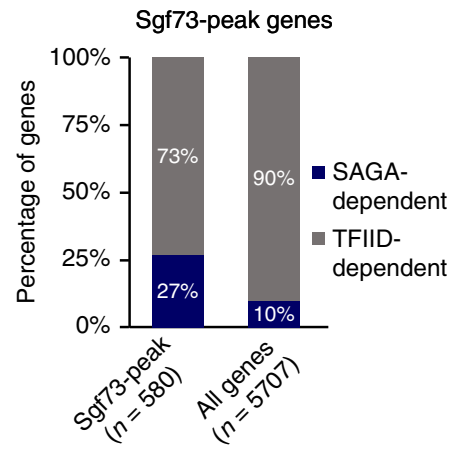

e

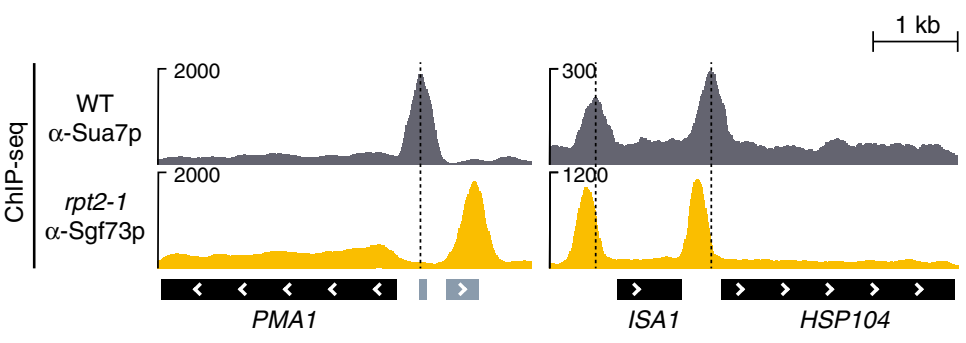

Distance from TSS $(\mathrm{kb})$

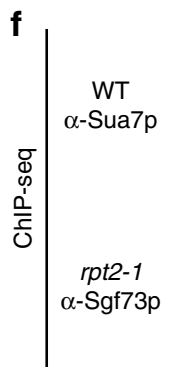

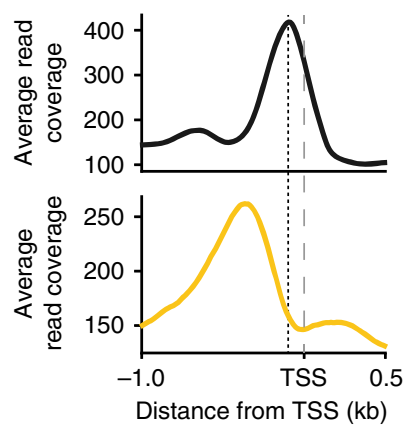

Fig. 3 Sgf73p is globally retained in the UAS elements of genes in rpt2-1. a Genome browser view of the PMA1, PGK1, HSP104, and SSA1 genes showing the ChIP-seq profiles of Sgf73p and Sgf11p in mock, wildtype, rpt2-1, and sgf73 $\Delta$ cells. b Heatmaps of ChIP-seq signals representing Sgf73-DUBm binding ( $\alpha$ Sgf73p and $\alpha$-Sgf11p) in wildtype, rpt2-1, and sgf73 cells $1 \mathrm{~kb}$ upstream and $0.5 \mathrm{~kb}$ downstream of the TSS in the Sgf73-peak gene set ( $n=580$ ). Heatmaps were divided into SAGA-dependent genes $(n=156)$ and TFIID-dependent genes $(n=424)$ and sorted in descending order of Sgf73p enrichment. The $y$ axis color scale indicates normalized ChIP-seq read count. $\mathbf{c}$ Pie chart showing the Sgf73-peak localization pattern. $\mathbf{d}$ Bar graph indicating the distribution of Sgf73-peak genes within the SAGA-dependent genes (73\%) and TFIID-dependent genes (27\%). e Genome browser view of the PMA1, ISA1, and HSP104 genes showing the ChIP-seq profiles of Sua7p in wildtype and Sgf73p in rpt2-1 cells. Dotted lines indicate Sua7p peak sites. $\mathbf{f}$ Average plots of ChIP-seq signals representing the binding of Sua7p and Sgf73p in wildtype and rpt2-1 cells. Dashed and dotted lines indicate the TSS and Sua7p-binding sites, respectively. kb, kilobase. TSS, transcription start site

part of the full SAGA complex, and that Sgf73-DUBm is subsequently separated by the proteasome for further downstream regulation.

SAGA has been implicated in regulating stress-inducible genes, whereas TFIID is believed to be responsible for controlling the expression of housekeeping genes ${ }^{28,29}$. However, there has been some controversy regarding this division of function, as recent reports suggest that the SAGA complex plays a broader role in regulating gene expression ${ }^{26,30}$. Interestingly, although the Sgf73DUBm peak genes identified in the present work did not show any particular tendency towards the SAGA-dependent or TFIIDdependent gene groups (Fig. 3b, d), we observed sharp Sgf73- 
DUBm peaks in some well-characterized stress-inducible genes, including heat shock genes (e.g., HSP104 and SSA1) (Fig. 3a). Based on these findings, we are convinced that the previous attempts to classify SAGA-regulated genes by simply depleting SAGA subunits and performing steady-state transcriptomic analysis were insufficient to fully reflect the regulatory dependency of genes. Rather, it seems likely that SAGA per se orchestrates the expression of various gene sets via a more dynamic mode of regulation.

\section{Sgf73p is required for proper chromatin recruitment of Yralp.} The physical interaction between Sgf73p and Yralp prompted us to use ChIP-seq analysis to assess the chromatin localization of Yralp regarding the Sgf73-peak gene set. In wildtype cells, Yralp showed a gradual increase in enrichment throughout the genebody region, as previously reported (Fig. $4 \mathrm{a})^{31-33}$. In the rpt2-1 mutant, Yralp was absent in the gene-body region and showed colocalization with Sgf73p in the UAS, confirming the physical interaction between the two factors (Fig. 4b). Interestingly, in the absence of Sgf73p, Yralp was also retained in the UAS and showed slightly reduced occupancy throughout the gene-body (Fig. 4a). Since no physical interaction was observed between Sgf73p and Pcf11p in vivo and Pcf11p enrichment was not significantly altered in the mutants (Supplementary Fig. 5a, b), we believe that Sgf73p is not likely to be directly responsible for the initial recruitment of Yralp. Additionally, although the tagging of Yralp with large epitopes (e.g., GFP) was reported to result in growth defects, we did not detect any noticeable growth defect due to the tagging of Yralp under our experimental conditions (Supplementary Fig. 5c, d).

Having observed that Sgf73p binds the same domain within Yralp that also binds Pcfl1p (Fig. 1e), we speculated that there could be competitive binding among Yralp, Sgf73p, and Pcf11p. To further characterize the interaction among Yralp, Sgf73p, and Pcf11p, we performed a competition assay in vitro (Fig. 4c). First, the Yralp-Pcf11p complex was assembled on immobilized GST beads. The bead-bound complexes were washed briefly, Sgf73p was added and the amount of Pcf11p released to the supernatant was assessed by Western blotting. As shown in Fig. 4d, the amount of released Pcfl1p gradually increased following the addition of Sgf73p. From these findings, we propose that Yralp is handed over from Pcf11p to Sgf73p for further regulation (see the section "Discussion" for details).

Yra1p loading onto nascent RNA transcripts requires Sgf73p. After its recruitment onto chromatin, Yralp recruits the essential mRNA export factors, Mex67p-Mtr2p, and is loaded onto nascent RNA transcripts along with other factors for subsequent steps of the mRNA export process $3,4,34$. However, the molecular mechanism responsible for transitioning Yralp from the transcriptional machinery to the nascent RNA is not yet fully understood.

Our Yralp ChIP-seq analysis showed that Yralp is significantly retained in the UAS and its enrichment along the gene-body is decreased in the $s g f 73 \Delta$ mutant compared to wildtype (Fig. 4a). Based on this data, we hypothesized that the loading of Yralp onto RNA is likely to be affected in this mutant. To analyze the changes in the RNA binding of Yralp, we performed in vivo RNA-immunoprecipitation (R-IP) assays for the PMA1 transcript in wildtype, $r p t 2-1$, and $s g f 73 \Delta$ cells. Yralp showed significantly reduced RNA-binding activity in the rpt2-1 mutant compared to wildtype (Fig. 4e), which likely reflects the retention of Yralp in the UAS. Surprisingly, the RNA binding of Yralp was reduced in the SGF73 deletion cells, to a level similar to that of rpt2-1. Given that enrichment of Yralp was observed throughout the gene- body in $s g f 73 \Delta$ cells (Fig. $4 a, s g f 73 \Delta$ ), the reduced R-IP signals indicate that the Yralp-RNA interaction is defective in the sgf $73 \Delta$ mutant. Similar patterns were observed for other representative transcripts, including those of PGK1, HSP104, and SSA1 (Supplementary Fig. 6a-c).

As the findings described above suggest that Sgf73p plays a role in transitioning Yralp onto RNA transcripts, we hypothesized that this could occur via the direct binding of RNA by Sgf73p. Our R-IP assays revealed that Sgf73p has a strong RNA-binding activity (Fig. $4 \mathrm{f}$ and Supplementary Fig. 6). To further confirm the RNA-binding activity of Sgf73p, we performed an in vitro RNA pulldown assay and RNA electrophoretic mobility shift assay (RNA-EMSA) using the GAL1 transcript. Consistent with our in vivo data, Sgf73p showed significant RNA binding in vitro (Supplementary Fig. 6d). Collectively, these findings indicate that Sgf73p is required for the proper loading of Yralp onto nascent transcripts, possibly through its direct binding with RNA.

Sgf73p specifically occupies the UASs of inducible genes. Motif analysis using HOMER indicated that there was a strong correlation between the binding sequences of Sgf73p and Hsflp (Fig. 5a). A recent study stringently identified genes that are directly regulated by yeast heat shock factor 1 (Hsf1) upon stress $^{35}$. Consistent with the motif analysis, Sgf73-DUBm peaks were found in the UASs of all $18 \mathrm{Hsf1} 1$-regulated genes in the rpt21 mutant (Supplementary Fig. 7a).

To investigate a possible stress-related function of Sgf73p, we analyzed the changes in Sgf73p retention during heat shock with respect to the Hsf1-dependent genes. Upon heat shock, we observed a significant increase in the enrichment of Sgf73p at the Hsf1-dependent gene set $(n=18)$ in wildtype cells (Fig. 5b). Interestingly, the intensity of Sgf73p retention was similar between wildtype and $r p t 2-1$ cells after heat shock. The Hsf1dependent genes were previously shown to be required for cell survival following other environment changes, including oxidative stress ${ }^{36}$. To test whether the enrichment of Sgf73p is heat shock-specific, we performed ChIP-qPCR against 5xFLAG-tagged Sgf73p under oxidative stress. Indeed, the Sgf73p peak increased in wildtype cells, to a level similar to that seen in rpt2-1 cells (Supplementary Fig. 8a, b).

In an effort to characterize a global function of Sgf73p retention, we assessed another inducible gene, GAL1. Using ChIP-qPCR, we observed significant retention of Sgf73p (approximately five-fold the wildtype level) within the GAL1 UAS of the non-induced rpt2-1 mutant (Fig. 5c, -Galactose). Surprisingly, galactose induction increased the occupancy of Sgf73p in wildtype cells to a level similar to that seen in rpt2-1 cells (Fig. 5c, +Galactose). To confirm the causal relationship between galactose induction and the increased retention of Sgf73p in wildtype cells, we assessed Sgf73p occupancy near the promoter regions of the PMA1 and SSA1 genes, whose expression levels should be minimally affected by galactose induction (Supplementary Fig. 8c). Our ChIP-qPCR results revealed that, in contrast to the GAL1 gene, the enrichment of Sgf73p at PMA1 and SSA1 genes differed significantly between wildtype and rpt2-1 cells. Thus, the increased Sgf73p enrichment at the UAS of the GAL1 gene appears to be a specific response to galactose induction.

Sgf73p plays a key role in proteostasis. To investigate the physiological consequences of Sgf73p retention during stress tolerance, we assessed the cell survival rate upon heat shock. Wildtype, $r p t 2-1$ and $s g f 73 \Delta$ cells were subjected to severe heat shock $\left(15 \mathrm{~min}\right.$ at $\left.52^{\circ} \mathrm{C}\right)$, plated on rich medium and incubated at a physiological temperature. $s g f 73 \Delta$ cells showed reduced cell 
a

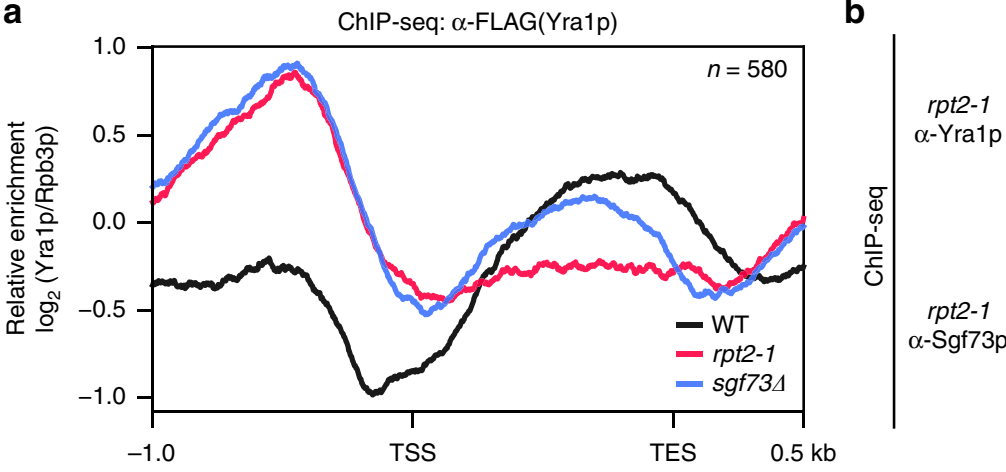

b

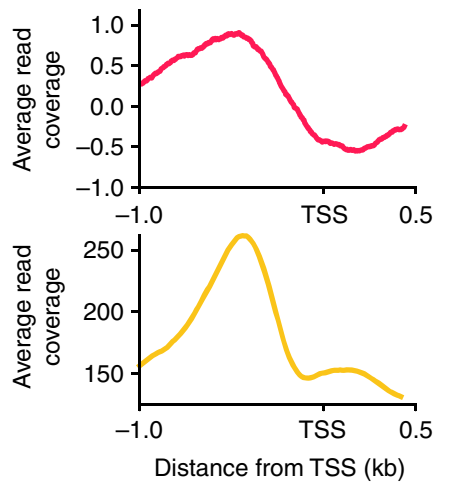

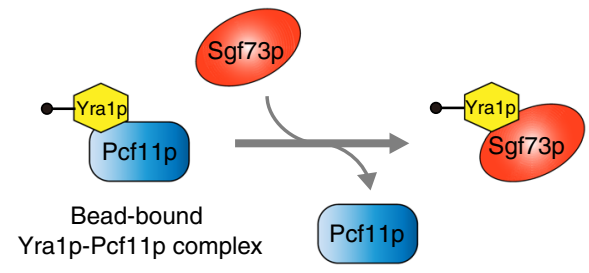

d

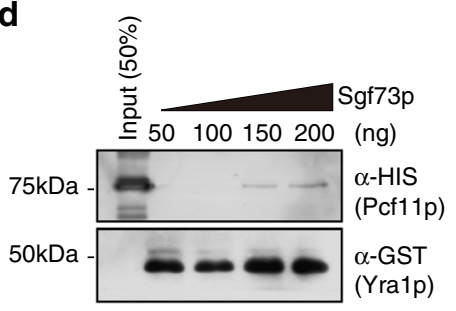

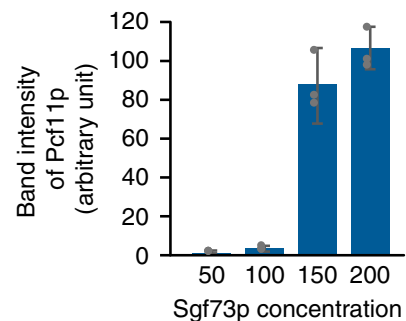

(ng)

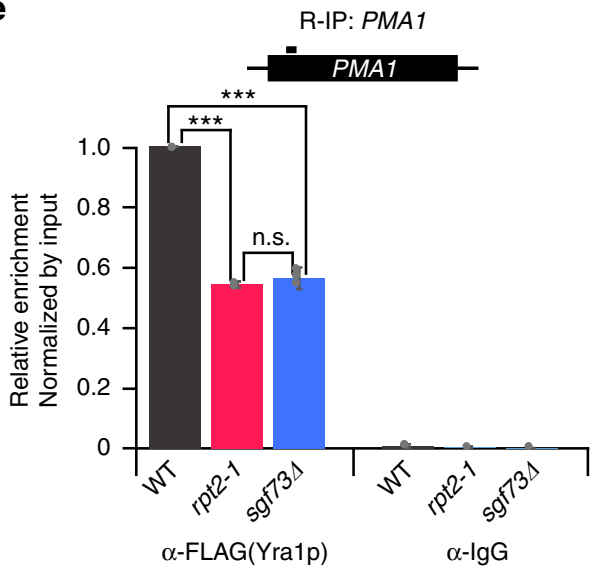

f

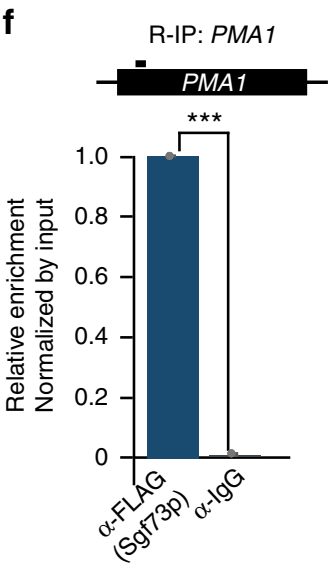

9 RNA pulldown: GAL1

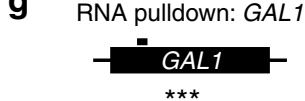

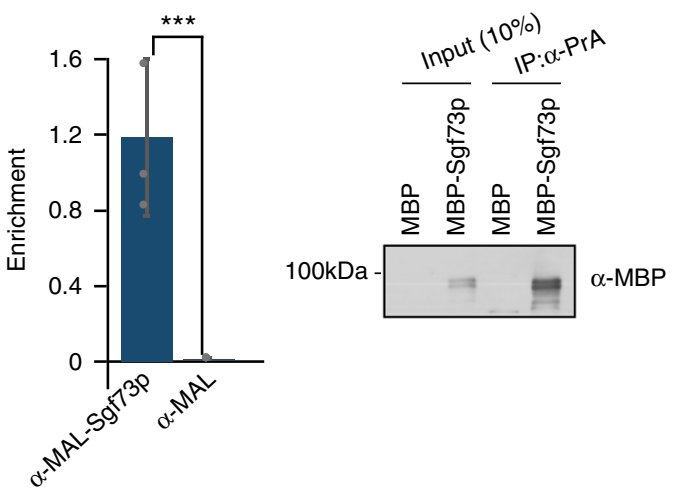

Fig. 4 Sgf73p participates in transitioning Yra1p onto nascent transcripts. a Average plots of ChIP-seq signals representing the binding of Yralp in wildtype, rpt2-1 and sgf73 $\Delta$ cells from $1.0 \mathrm{~kb}$ upstream of the TSS to $0.5 \mathrm{~kb}$ downstream of the TES, regarding the Sgf73-peak gene set $(n=580)$. b Average plots of ChIP-seq signals representing the binding of Yra1p and Sgf73p in the rpt2-1 mutant. c Schematic diagram of in vitro competition assay between Sgf73p and Pcf11p with respect to Yra1p binding. The Yra1p-Pcf11p complex was immobilized on GST sepharose beads. After a brief wash, Sgf73p was added and the amount of released Pcf11p in supernatants was assessed by Western blotting. d (Left panel) Western blotting of an in vitro competition assay performed between Sgf73p and Pcf11p ( $\alpha$-HIS) with respect to the binding of Yra1p ( $\alpha$-GST). (Right panel) Band intensity of released Pcf11p in the supernatant following the addition of Sgf73p. e R-IP-qPCR analysis of Yra1p ( $\alpha$-FLAG) and control ( $\alpha$-lgG) against the PMA1 transcript in wildtype, rpt2-1, and sgf73 $\Delta$ cells. f R-IP-qPCR analysis of Sgf73p ( $\alpha$-FLAG) and control ( $\alpha-\operatorname{lgG})$ against the PMA1 transcript in wildtype cells. $\mathbf{g}$ (Left panel) In vitro RNA-pulldown analysis of Sgf73p ( $\alpha$-MBP) against the GAL1 transcript. (Right panel) Western blotting against bead-bound Sgf73p ( $\alpha-M B P$ ). Standard deviations of all quantification data were obtained from three independent experiments and are shown by error bars; $P$-values were evaluated by Student's $t$-test $\left({ }^{\star} P \leq\right.$ $0.05,{ }^{\star \star} P \leq 0.01$, and $\left.{ }^{\star \star \star} P \leq 0.001\right)$. kb, kilobase. TSS, transcription start site. TES, transcription end site

survival upon heat shock (Fig. 5d). Moreover, we found that Sgf73p is required for heat shock survival in other isogenic backgrounds, including W303a and BY4741 (Supplementary Fig. 8d). Consistent with the above-described ChIP-qPCR results, the $\operatorname{sgf} 73 \Delta$ mutant showed reduced tolerance to oxidative stress and a decreased growth rate in galactose-based medium (Supplementary Fig. 8e, f).

Most of the Hsf1-dependent genes encode chaperone transcripts and thus are closely related to proteostasis. To directly observe the function of Sgf73p in proteostasis upon heat shock, we utilized the GFP-tagged Ubc9ts mutant protein. Upon heat shock, Ubc9ts proteins form distinctive foci that are eventually resolved by the ubiquitin-proteasome pathway in wildtype cells, whereas they are retained in proteostasis-compromised mutants ${ }^{37,38}$. After $2 \mathrm{~h}$ of heat shock, wildtype cells displayed complete elimination of Ubc9ts foci, whereas the proteolytic mutant, cim3-1, still displayed distinctive foci (Fig. 5e) ${ }^{39}$. Consistent with the findings described above, the $s g f 73 \Delta$ mutant exhibited Ubc9ts foci similar to those found in the cim3-1 mutant. To confirm the imaging data, we prepared whole-cell extracts from heat-shocked cells and used Western blotting to quantify the GFP-Ubc9ts protein levels. After $2 \mathrm{~h}$ of heat shock, the Sgf73p 
a

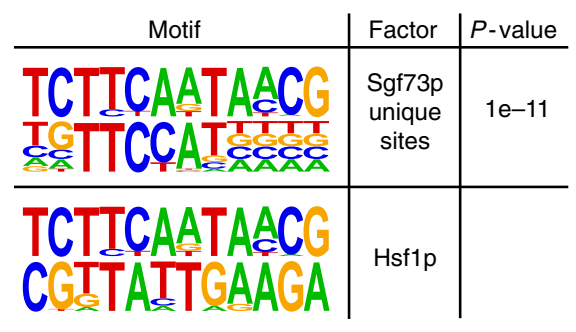

C

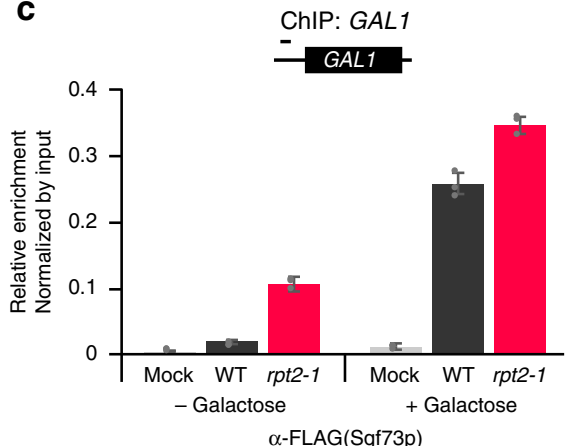

d

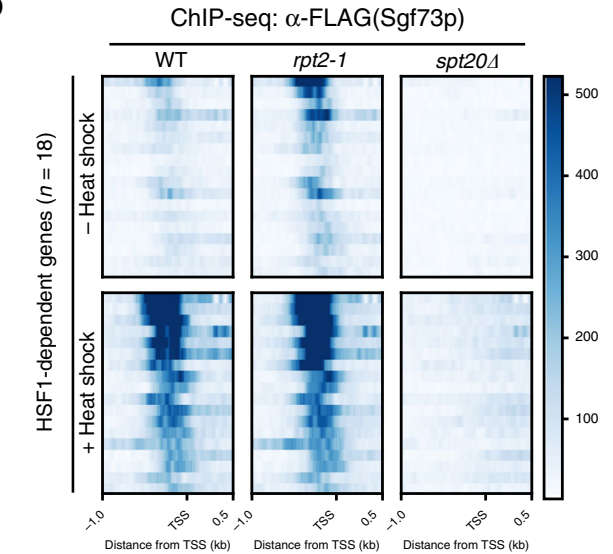

e

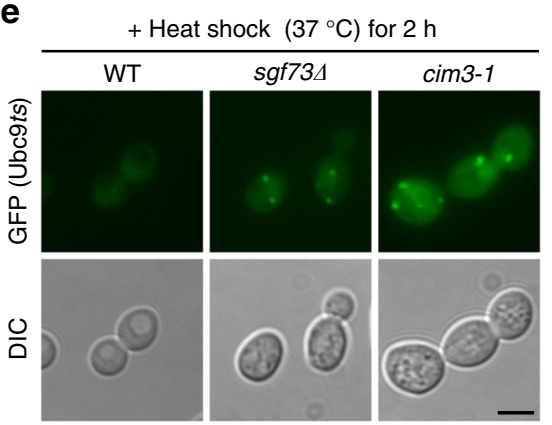

f

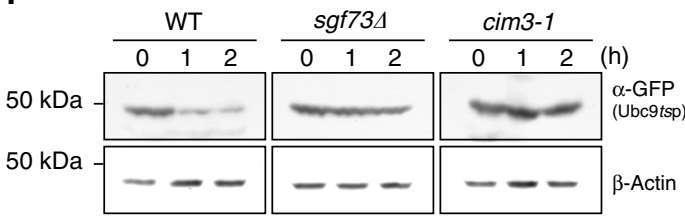

Fig. 5 Sgf73p is required for heat shock survival and proteostasis. a (Upper panel) De novo motif enrichment analysis of Sgf73p-binding sites was performed using HOMER. (Lower panel) Comparison of the Sgf73p-binding motif with known motifs showed significant correspondence with the Hsf1pbinding motif. b Heatmaps of ChIP-seq signals representing Sgf73p-binding ( $\alpha$-FLAG) in wildtype, rpt2-1, and spt20 cells, from $1 \mathrm{~kb}$ upstream to $0.5 \mathrm{~kb}$ downstream of the TSS regarding Hsf1-dependent genes $(n=18)$ before and after heat shock. Heatmaps were sorted in descending order of Sgf73p enrichment. The $y$-axis color scale indicates normalized ChIP-seq read count. c ChIP-qPCR analysis against Sgf73p ( $\alpha$-FLAG) of the GAL1 gene before and after galactose induction in mock, wildtype, and rpt2-1 cells. $\mathbf{d}$ Cell survival analysis after heat shock was assessed by spotting assays. Wildtype, rpt2-1, and sgf $73 \Delta$ cells were subjected to heat shock at $52^{\circ} \mathrm{C}$ for $15 \mathrm{~min}$, plated on YPD medium in five-fold serial dilutions, and incubated at $25^{\circ} \mathrm{C}$ for 3 days. e Visualization of GFP-Ubc9ts by fluorescence imaging. Wildtype, rpt2-1 and sgf73 $\Delta$ cells carrying the galactose-inducible GFP-Ubc9ts construct were subjected to heat shock at $37^{\circ} \mathrm{C}$ for $2 \mathrm{~h}$, and then fixed and imaged. Scale bar, $5 \mu \mathrm{m}$. f GFP-Ubcp9ts protein levels ( $\alpha$-GFP) in wildtype, rpt2-1, and sgf73 $\Delta$ cells subjected to heat shock were assessed by Western blotting. $\beta$-Actin was used as a loading control. Standard deviations of three independent experiments are shown by error bars. kb, kilobase. TSS, transcription start site

deletion mutant showed a significantly higher level of GFPUbc9ts proteins compared to wildtype cells (Fig. 5f).

Overall, these findings show that the retention of Sgf73p in the UAS of specific genes is required for stress tolerance and cell survival.

Sgf73p retention promotes non-canonical mRNA export. Having shown that Sgf73p plays roles in proteostasis and the regulation of Hsf1-dependent genes during stress, we speculated that Sgf73p is likely to promote the efficient export of stressinducible transcripts. To directly assess the possible function of
Sgf73p in the export of Hsf1-dependent transcripts during stress, we performed single-molecule FISH (smFISH) against the stressinducible HSP12 RNA after heat shock. As shown in Fig. 6a, we observed significant retention of the HSP12 transcript in the sgf73 mutant, similar to that seen in mex67-5. ChIP-qPCR analysis confirmed that there was significant accumulation of Sgf73p on the inducible promoter/UAS $P_{H S P 12}$ upon heat shock in wildtype cells, whereas none was observed on the non-Hsflpdependent $P_{C Y C 1}$ (Fig. 6d). When the promoter/UAS of the CYC1 gene was replaced with that of $H S P 12$, we observed proper $C Y C 1$ transcript export and Sgf73p retention in wildtype cells 
a

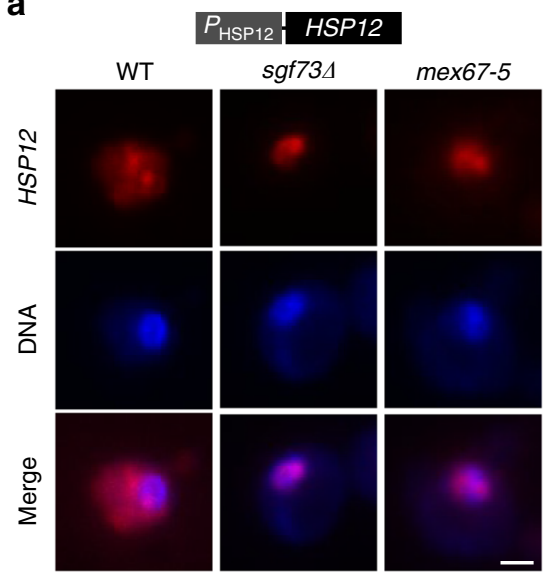

b

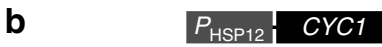

d

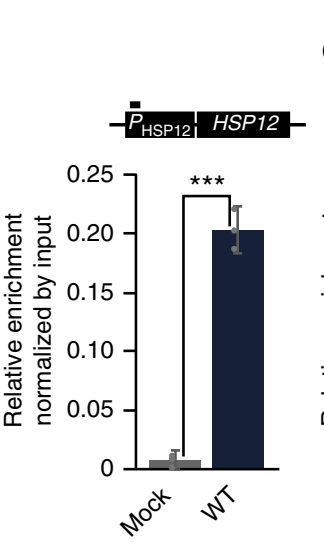

+ Heat shock

ChIP-seq: $\alpha-F L A G($ Sgf73p)
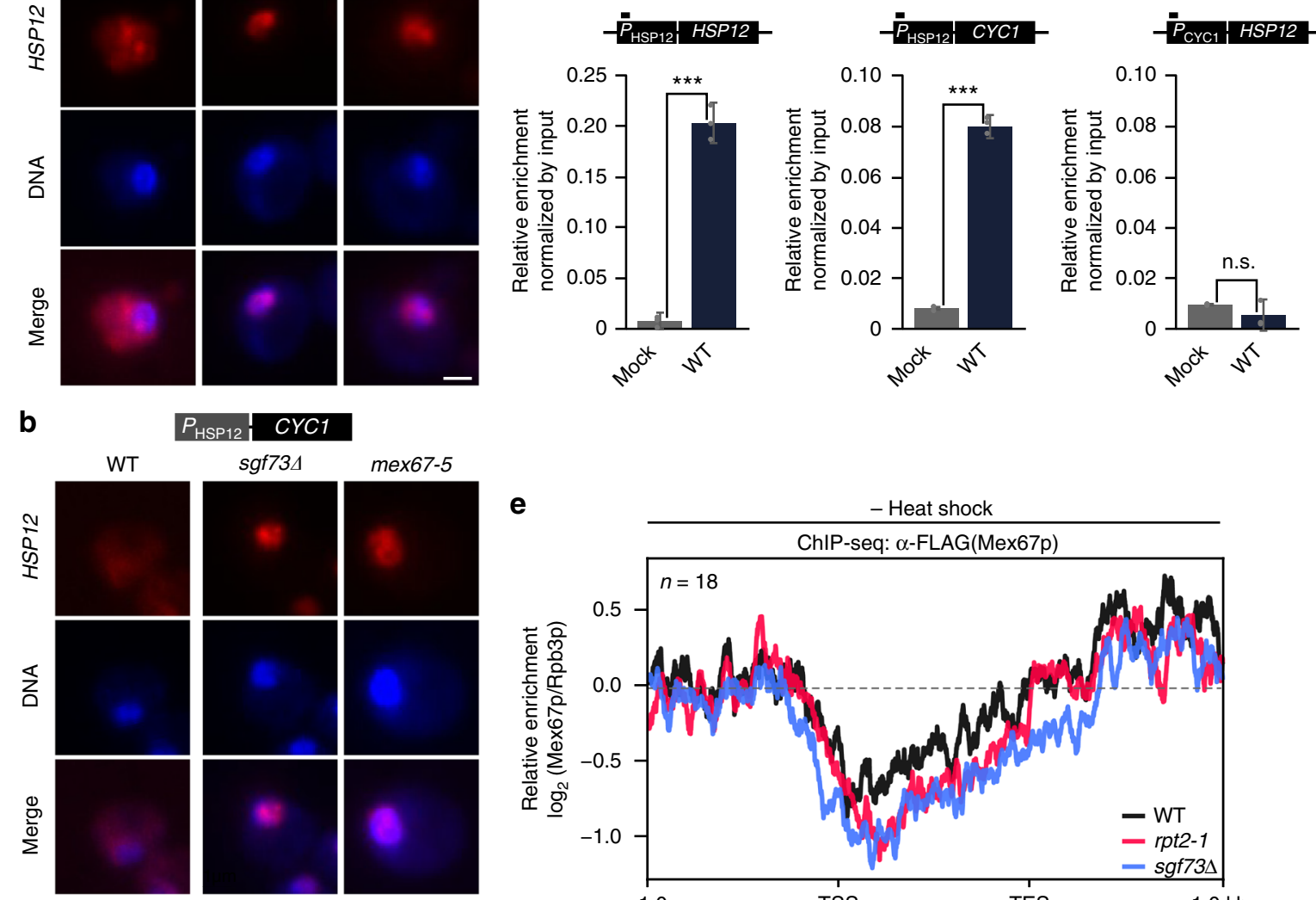

sgf734

$\operatorname{mex} 67-5$

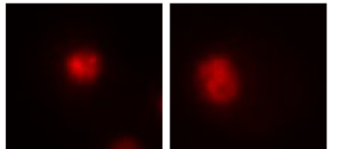

e

- Heat shock

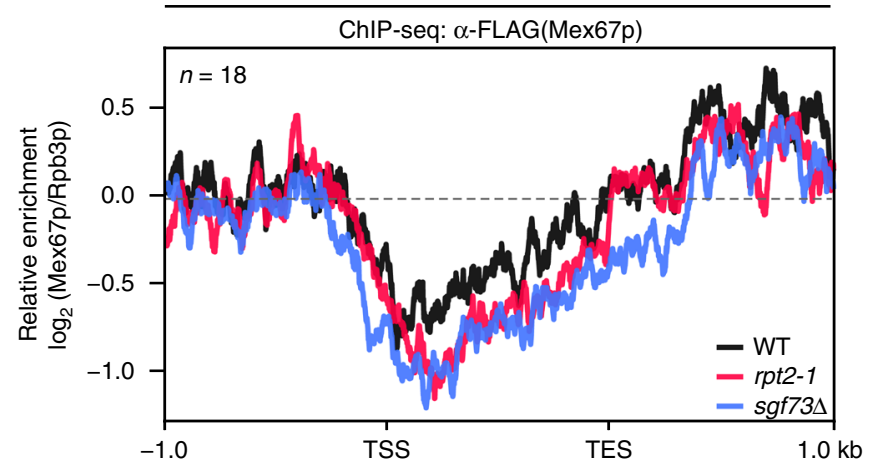

C
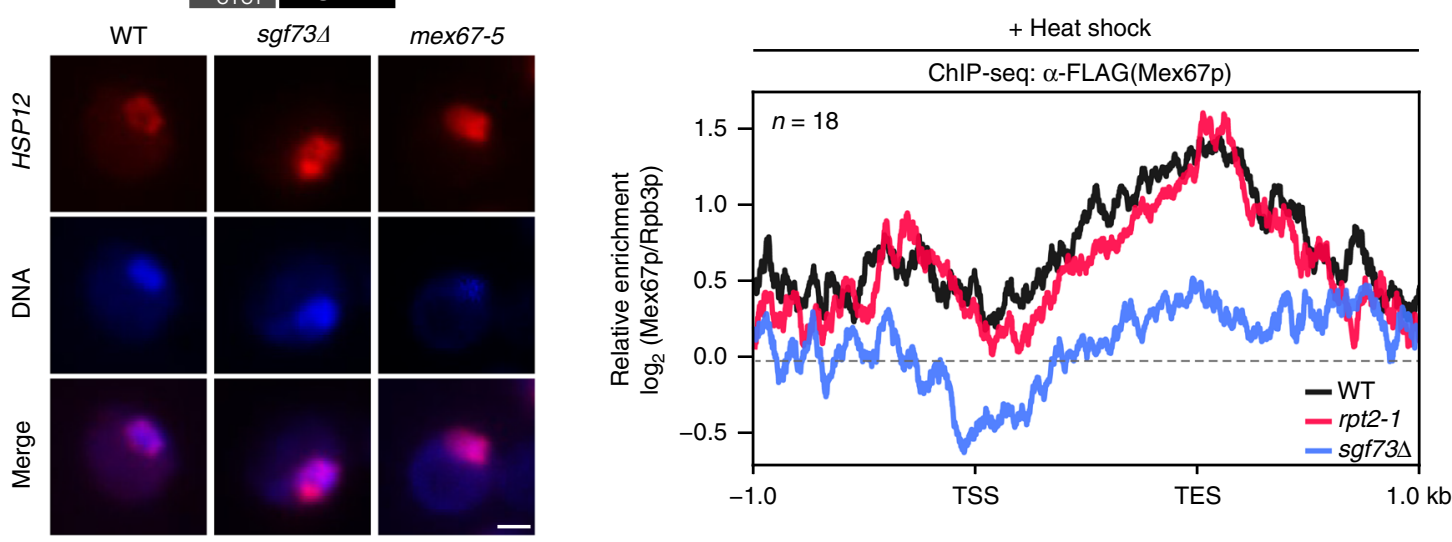

Fig. 6 Sgf73p promotes export of specific transcripts during heat shock. a-c FISH analyses against (a) stress-inducible $\mathrm{P}_{\mathrm{HSP} 12}$ HSP12, (b) stress-inducible $\mathrm{P}_{\mathrm{HSP12}} \mathrm{CYC1}$, and (c) non-inducible $\mathrm{P}_{\mathrm{CYC1}}$ HSP12 genes were performed using Cy3-labeled specific probes. DNA was counterstained with DAPI. Scale bar, 1 $\mu \mathrm{m}$. d ChIP-qPCR analysis against Sgf73p ( $\alpha$-FLAG) in mock and wildtype cells after heat shock, regarding a stress-inducible promoter (left and middle panel) and a non-inducible promoter (right panel). e Average plot of Mex67-5xFLAG enrichment in wildtype, rpt2-1, and sgf73 cells with respect to the Hsf1-dependent gene set $(n=18)$ before and after heat shock. Standard deviations obtained from three independent experiments are shown by error bars and $P$-values were determined by Student's $t$-test $\left({ }^{\star} P \leq 0.05,{ }^{\star \star} P \leq 0.01\right.$, and $\left.{ }^{\star \star \star} P \leq 0.001\right)$

(Fig. 6b-d), suggesting that Sgf73p accumulation is important for the export of stress-inducible transcripts upon heat shock. Additionally, we observed a physical interaction between Sgf73p and Hsflp in vivo (Supplementary Fig. 9a). Together, our data show that Sgf73p plays an essential role in the specific export of Hsf1-dependent transcripts during stress.

A recent report demonstrated that Mex67p alone has an independent function in the immediate mRNA export of certain transcripts, such as those encoding chaperones, during heat shock $^{40}$. The same study showed that, during this process, canonical mRNA export factors are absent from the transcripts and quality control is bypassed for timely export. We performed ChIP-seq analysis against 5xFLAG-tagged Mex67p in wildtype, $r p t 2-1$, and $s g f 73 \Delta$ cells before and after heat shock (Fig. 6e). Interestingly, the levels of Mex67p were similar in wildtype, $r p t 2$ 1 , and $s g f 73 \Delta$ cells under normal growth conditions, whereas Mex67p enrichment was significantly reduced in the $s g f 73 \Delta$ mutant under heat shock. Additionally, the enrichment of 
Mex67p at non-Hsflp genes did not significantly differ in wildtype, rpt2-1, and sgf73 cells (Supplementary Fig. 9b, c). Based on these data, we propose the following model: During environmental stress, such as heat shock, the retention of Sgf73p at UASs is required to withhold canonical mRNA export factors, including Yralp, allowing certain mRNAs to bypass the quality control system and undergo immediate export mediated by Mex67p alone.

Taken together, our data indicate that Sgf73p orchestrates the selective and efficient export of target genes in response to specific environmental cues, and that this occurs through a direct interaction with various mRNA export factors.

\section{Discussion}

In this report, we show that Sgf73p of the SAGA deubiquitylating module directly interacts with the essential mRNA export factor, Yralp, and is required for its proper chromatin localization and binding of nascent RNA. Under physiological conditions, Sgf73p, in conjunction with the central surveillance factor Rrp6p, oversees the nucleocytoplasmic translocation of export-competent mRNPs. Upon receipt of an environmental stimulus, such as heat shock stress or galactose induction, Sgf73p initiates the noncanonical mRNA export pathway, which is subject to minimal quality control, and facilitates the prompt export of selective gene sets (Fig. 7). Thus, Sgf73p-mediated switching between the canonical and non-canonical mRNA export pathways orchestrates the plasticity of gene expression to maximize cell survival.

mRNA export is a tightly coordinated process during which various factors are co-transcriptionally recruited to the transcription site and nascent RNA. Previous studies have shown that the RNA polymerase II (RNAPII) CTD-bound Pcfllp is responsible for recruiting Yralp to the transcription site. Our findings here show that Sgf73p physically interacts with Yralp, but not with Pcf11p. Additionally, our in vitro competition assay indicates that Pcf11p and Sgf73p competes in binding Yralp. Based on these findings, we prefer the model in which Yralp is initially recruited to chromatin by Pcf11p and is handed-over to Sgf73p for further processes of mRNA export. However, further investigation is needed to fully describe the complex network among these factors, including a more comprehensive analysis of the chromatin localization.

The SAGA complex is composed of four distinct modules, two of which have enzymatic activities: the histone acetyltransferase module and the histone deubiquitylating module (DUBm). SAGA was initially shown to be important for both transcriptional activation and elongation ${ }^{41,42}$, and recent work has highlighted its role in mRNA export, especially through the DUBm ${ }^{12,15}$. Here, we report direct evidence showing that SAGA contributes to the biogenesis quality control and export of mRNPs through the DUBm subunit, Sgf73p. Our findings strongly support the notion that SAGA intricately coordinates gene expression from the
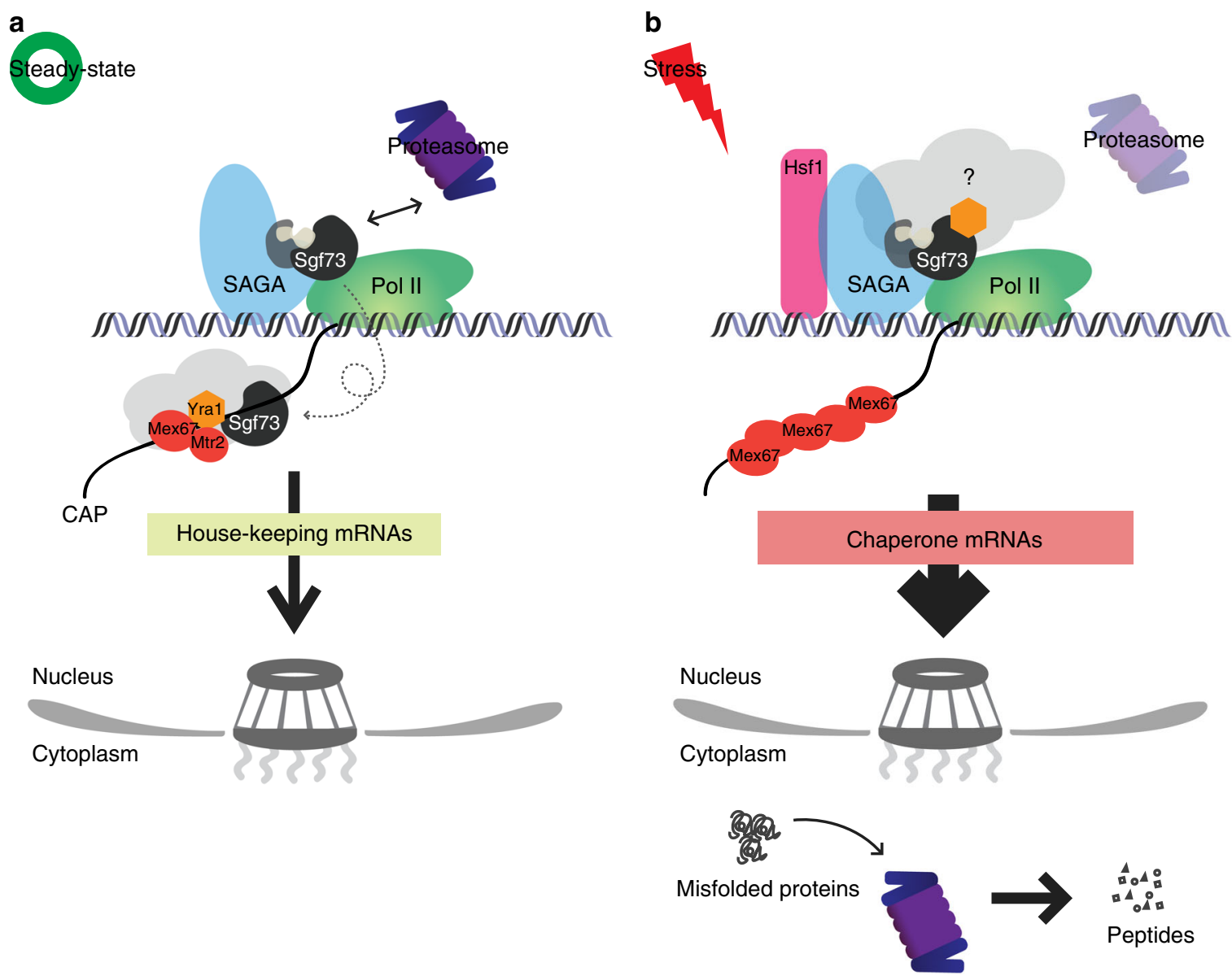

Fig. 7 Sgf73p-mediated mRNP surveillance facilitates proteostasis. a Under physiological conditions, the proteasome-dependent separation of the Sgf73DUBm from SAGA is required for surveillance of mRNP biogenesis. The physical interaction between Sgf73p and Yralp facilitates proper chromatin recruitment and RNA binding of Yra1p. b During stress, Sgf73p accumulates in the UASs of specific genes, and Sgf73p retention initiates the Mex67pmediated non-canonical mRNA export pathway to bypass quality control. Overall, Sgf73p regulates the plasticity of gene expression by interacting with key mRNA export factors to maintain proteostasis and maximize cell survival under environmental uncertainty 
activation step through elongation and export. We believe that the arrangement of functional modules within SAGA serves as an efficient platform for the proteasome to regulate proteostasis and effectively respond to environmental stress.

In the last decade, it was widely accepted that there was a clear distinction between the SAGA-dependent and TFIID-dependent gene sets, and that SAGA and TFIID specifically regulated stressrelated and housekeeping genes, respectively ${ }^{28}$. However, recent studies have questioned the accuracy of this classification ${ }^{26,30}$. In an effort to newly define genes that are directly regulated by the SAGA complex, we herein identified the Sgf73-peak gene set. This gene set did not show any prevalent bias towards either SAGAdependent or TFIID-dependent genes, indicating that the regulatory jurisdiction of SAGA is not confined to the previously defined gene set. Instead, we propose that the SAGA complex executes a more complicated and dynamic mode of gene expression regulation.

The proteasome is believed to confer non-proteolytic functions through its chaperone-like activity. For example, the 19S RP of the proteasome has been demonstrated to stimulate promoter targeting of co-activators ${ }^{43}$ and contribute to transcriptional elongation through an interaction with the FACT complex ${ }^{44,45}$. We previously showed that a physical interaction between the $19 \mathrm{~S}$ RP and Sgf73p of SAGA is critical for proper mRNA export ${ }^{10}$. Here, we report that, upon environmental stress (e.g., heat shock and oxidative stress), Sgf73p selectively occupies the UASs of molecular chaperone transcripts, which are required for cell survival during stress ${ }^{46}$. Given that the release of Sgf73-DUBm from the SAGA complex is facilitated by the 19S RP, our findings suggest that there is a close relationship between the proteolytic and non-proteolytic functions of the proteasome, both of which contribute to proteostasis (Fig. 7).

In agreement with our findings, starvation in yeast was reported to induce up-regulation of Hsflp targets ${ }^{47}$. The GAL1 gene encodes the Gallp galactokinase, which catalyzes the conversion of $\alpha$-D-galactose to galactose-1-phosphate; in the absence of Gallp, galactose catabolism is perturbed and cells display a proteotoxic phenotype ${ }^{48}$. Thus, consistent with cells under heat shock and oxidative stress, cells grown in galactose-based medium require the concerted function of Sgf73p and the proteasome for survival. Altogether, our findings here demonstrate a comprehensive role of the proteasome in protein homeostasis regulation.

\begin{abstract}
Methods
Yeast strains and plasmid construction. The strains and plasmid constructs used in this study are detailed in Supplementary Tables 1 and 2, respectively. Genomic integration of C-terminal tags and gene deletions were performed by homologous recombination of PCR fragments ${ }^{49}$. Cells were cultured in yeast peptone dextrose (YPD) medium at $30^{\circ} \mathrm{C}$ unless otherwise indicated. For galactose induction assays, cells were cultured in YP $+2 \%$ raffinose medium to mid-log phase and an additional 2\% galactose was added. Plasmid constructs were prepared using an EZFusion Cloning Kit (Enzynomics, EZ015).
\end{abstract}

Spotting assay. Cells were spotted onto the indicated plates with a starting OD of 0.5 and five-fold serial dilutions, unless otherwise noted. Plates were incubated at the indicated temperatures for $\sim 2-3$ days.

Co-immunoprecipitation. Cells were cultured to mid-log phase, harvested by centrifugation (total of 20OD), resuspended in NP40 lysis buffer [1\% NP40, 150 $\mathrm{mM} \mathrm{NaCl}, 2 \mathrm{mM}$ EDTA, $6 \mathrm{mM} \mathrm{Na}_{2} \mathrm{HPO}_{4}, 4 \mathrm{mM} \mathrm{NaH}_{2} \mathrm{PO}_{4}$, and protease inhibitors] and lysed by bead beating at $4{ }^{\circ} \mathrm{C}$. Cell lysates were centrifuged at $13,000 \mathrm{rpm}$ for $20 \mathrm{~min}$ at $4^{\circ} \mathrm{C}$, mixed with IgG or M2 beads (GE Healthcare, 17-0969-01, and Sigma, A2220, respectively) and incubated at $4{ }^{\circ} \mathrm{C}$ for $2 \mathrm{~h}$ with agitation. The beads were washed three times with $1 \mathrm{ml} \mathrm{NP} 40$ lysis buffer, and the bound proteins were eluted by boiling at $100^{\circ} \mathrm{C}$ for $5 \mathrm{~min}$ in $2 \mathrm{X}$ SDS sample buffer and quantified by Western blotting (anti-MYC antibody; in-house; 1:3000, anti-FLAG M2 antibody; Sigma; F1804; 1:3000). Uncropped Western-blots can be found in Supplementary Figs. 10 and 11.
Affinity purification. For TAP-tagged protein purification, yeast cells were grown in YPD at $30^{\circ} \mathrm{C}$ to an OD of $\sim 1.0$, harvested, resuspended in Workman buffer [ 40 $\mathrm{mM}$ HEPES-KOH (pH 7.5), $350 \mathrm{mM} \mathrm{NaCl}, 10 \%$ glycerol, $0.1 \%$ Tween- 20 , and protease inhibitors] and lysed using a mixer mill (Retsch, MM400). Cell extracts were subjected to a brief centrifugation and the collected supernatants were applied to IgG Sepharose (GE Healthcare, 17-0969-01) for $3 \mathrm{~h}$, and then to $5 \mu \mathrm{g}$ TEV overnight at $4{ }^{\circ} \mathrm{C}$. The TEV-treated supernatants were mixed with calmodulin sepharose (Stratagene, 214303) in Calmodulin-binding buffer $[10 \mathrm{mM}$ Tris-HCl (pH 8.0), $1 \mathrm{mM} \mathrm{MgAc}, 1 \mathrm{mM}$ imidazole, $2 \mathrm{mM} \mathrm{CaCl}_{2}, 0.1 \% \mathrm{NP} 40,10 \mathrm{mM} \beta$ mercaptoethanol, $300 \mathrm{mM} \mathrm{KCl}, 10 \%$ glycerol, and protease inhibitors]. Bound proteins were eluted in Calmodulin elution buffer [10 mM Tris- $\mathrm{HCl}(\mathrm{pH} 8.0), 150$ $\mathrm{mM} \mathrm{NaCl}, 1 \mathrm{mM}$ MgAc, $1 \mathrm{mM}$ imidazole, $3 \mathrm{mM}$ EGTA, 0.1\% NP40, 10\% glycerol, and protease inhibitors] and analyzed by Western blotting (anti-CBP antibody; inhouse: 1:3000).

In vitro protein-pulldown assay. Bait protein $(1 \mu \mathrm{g})$ and $200 \mathrm{ng}$ target protein were mixed with $50 \mu$ l Pulldown buffer [50 mM HEPES-KOH (pH 7.5), $150 \mathrm{mM}$ $\mathrm{NaCl}, 10 \%$ glycerol, $0.1 \% \mathrm{NP} 40,0.5 \mathrm{mM}$ DTT, $1 \mathrm{mM}$ EDTA, and protease inhibitors] and $10 \mu \mathrm{l}$ of beads, and incubated at $4{ }^{\circ} \mathrm{C}$ for $2 \mathrm{~h}$. The protein-bound beads were washed three times with $1 \mathrm{ml}$ Pulldown buffer. The bound proteins were eluted by boiling at $100^{\circ} \mathrm{C}$ for $5 \mathrm{~min}$ in $20 \mu \mathrm{l}$ X SDS sample buffer, and quantified by Western blotting (anti-HA antibody; in-house; 1:3000, anti-FLAG M2 antibody; Sigma; F1804; 1:3000, anti-MBP antibody; in-house; 1:3000).

Fluorescence in situ hybridization and imaging. Cells were cultured to early logphase (0.2OD) and pre-fixed in 0.1 volume of $37 \%$ formaldehyde for $15 \mathrm{~min}$ at room temperature. The cells were harvested by centrifugation and fixed in $10 \mathrm{ml}$ $4 \%$ para-formaldehyde (Alfa Aesar) in phosphate buffer for $3 \mathrm{~h}$ at room temperature with agitation. The cells were briefly washed twice using $10 \mathrm{ml}$ ice-cold Solution B [1.2 M sorbitol and $\left.0.1 \mathrm{M} \mathrm{KPO}_{4}\right]$ and resuspended in $500 \mu \mathrm{l}$ Zymolase B [Solution B and $0.2 \% \beta$-mercaptoethanol] and $50 \mu \mathrm{l} 10 \mathrm{mg} / \mathrm{ml}$ 20T Zymolase (USBiological) to prepare spheroplasts. Permeabilized cells were washed using $1 \mathrm{ml}$ ice-cold Solution B, and applied to poly-L-lysine (Sigma)-coated cover slips. The cells were then treated with pre-hybridization B [ $10 \%$ dextran sulfate, $0.2 \% \mathrm{BSA}$, $0.3 \mathrm{M} \mathrm{NaCl}, 30 \mathrm{mM}$ trisodium citrate dehydrate, $125 \mu \mathrm{g} / \mathrm{ml}$ yeast tRNA, $500 \mu \mathrm{g} / \mathrm{ml}$ denatured sonicated ssDNA, and $0.1 \mathrm{U} / \mu \mathrm{l}$ RNasin] and incubated in a humid chamber at $37^{\circ} \mathrm{C}$ for $1 \mathrm{~h}$. After being washed with 2X SSC B $[0.3 \mathrm{M} \mathrm{NaCl}$ and 30 $\mathrm{mM}$ trisodium citrate dehydrate], the cells were treated with Hybridization B [Prehybridization B plus $1 \mathrm{ng} / \mathrm{ml}$ Cy3-labeled oligo dT (50) probe] and incubated in a humid chamber at $37^{\circ} \mathrm{C}$ overnight. Nuclei were counterstained using $25 \mathrm{ng} / \mathrm{ml}$ 4',6-diamidino-2-phenylindole (DAPI). After two brief washes using distilled water, the cover slips were mounted onto slide glasses. Microscopy was performed using an Imager M1 fluorescence microscope equipped with an AxioCam HRm camera and the Axio Vision 4.3 software (Zeiss). Images were acquired using a $\times 100$ oil immersion lens and filter sets $20(488020-0000)$ and 49 (488049-0000) for $\mathrm{Cy} 3$ and DAPI signals, respectively (Zeiss). For smFISH, probes were designed against the GFP sequence as previously described ${ }^{40}$ (LGC Biosearch Technologies) and images were acquired using an Andor Zyla 4.2 sCMOS camera. Signal intensities were quantified using the ImageJ software ${ }^{50}$.

Chromatin immunoprecipitation. Cells were cultured under appropriate conditions and fixed with $1 \%$ (final concentration) formaldehyde for $15 \mathrm{~min}$ at room temperature with shaking. Fixation was stopped by the addition of glycine (final concentration, $125 \mathrm{mM}$ ). Cells were harvested by centrifugation, washed once using ice-cold 1X TBS buffer [ $20 \mathrm{mM}$ Tris- $\mathrm{HCl}(\mathrm{pH} \mathrm{7.5)}$ and $150 \mathrm{mM} \mathrm{NaCl}]$, and lysed in FA-M2 lysis buffer [50 mM Tris-HCl (pH 7.5), $150 \mathrm{mM} \mathrm{NaCl}, 1 \mathrm{mM}$ EDTA and $1 \%$ Triton X-100] with bead beating at $4{ }^{\circ} \mathrm{C}$. Supernatants were collected and subjected to sonication (Branson, 550) for chromatin shearing. The sonication conditions were optimized to obtain fragment lengths of 200-500 bp. The sonicated extracts were centrifuged at $13,000 \mathrm{rpm}$ for $20 \mathrm{~min}$ at $4{ }^{\circ} \mathrm{C}$, and the supernatants were incubated with $1 \mu \mathrm{g}$ of anti-FLAG M2 antibody (Sigma, F1804, $1 \mathrm{mg} /$ $\mathrm{ml}$ ) and $20 \mu \mathrm{l}$ Protein G Sepharose (GE Healthcare, 17-0618-50) at $4^{\circ} \mathrm{C}$ overnight with rotation. After stringent washes, the immunoprecipitated chromatin was eluted using ChIP elution buffer [50 mM Tris-HCl (pH 8.0), $10 \mathrm{mM}$ EDTA, and $1 \% \mathrm{SDS}]$ at $65^{\circ} \mathrm{C}$ with agitation. Eluted and input DNA were treated with RNase A $\left(10 \mu \mathrm{g}\right.$ for $1 \mathrm{~h}$ at $37^{\circ} \mathrm{C}$; Roche, 1010916900$)$ and proteinase $\mathrm{K}\left(60 \mu \mathrm{g}\right.$ for $2 \mathrm{~h}$ at $55^{\circ}$ C; Promega, V3021), and decrosslinked at $65^{\circ} \mathrm{C}$ overnight. The final ChIP DNA was purified using a QIAquick PCR Purification Kit (QIAGEN, 28106). Quantitative analyses were performed using a CFX96 Real-Time System (Bio-Rad, C1000 Thermal Cycler). The utilized primers are listed in Supplementary Table 3.

ChIP-seq library preparation and data analysis. ChIP-seq libraries were prepared using a NEXTflex ChIP-Seq Kit (Bioo Scientific Corporation, 5143-02) according to the manufacturer's protocol. Sequencing was performed on a HiSeq2500 platform (single-end, $50 \mathrm{bp}$ ). Sequenced reads were mapped to the $S$. cerevisiae genome (sacCer3) and processed using Bowtie $2^{51}$ and SAMtools ${ }^{52}$. Significant peaks were identified and annotated using $\mathrm{HOMER}^{25}$. Quantification analyses and average plots were generated using DeepTools ${ }^{53}$. 
RNA-immunoprecipitation. Cells cultured at appropriate conditions were fixed with $1 \%$ (final concentration) formaldehyde for $15 \mathrm{~min}$ at room temperature with shaking. Fixation was stopped by the addition of glycine (final concentration, 125 $\mathrm{mM}$ ). Cells were harvested by centrifugation, washed once using ice-cold 1X TBS buffer [20 mM Tris- $\mathrm{HCl}(\mathrm{pH} 7.5)$ and $150 \mathrm{mM} \mathrm{NaCl}$, and lysed in FA-M2 lysis buffer [50 mM Tris- $\mathrm{HCl}$ (pH 7.5), $150 \mathrm{mM} \mathrm{NaCl}, 1 \mathrm{mM}$ EDTA, 1\% Triton X-100 and $40 \mathrm{U} / \mathrm{ml} \mathrm{RNasin}$ ] with bead beating at $4{ }^{\circ} \mathrm{C}$. Cell extracts were subjected to sonication and centrifugation at $13,000 \mathrm{rpm}$ for $20 \mathrm{~min}$ at $4{ }^{\circ} \mathrm{C}$, and $500 \mu \mathrm{g}$ of supernatant was mixed with $10 \mu \mathrm{l}$ Dynabeads Protein G (Invitrogen, 10003D) and $1 \mu \mathrm{g}$ anti-FLAG antibody or anti-mouse IgG (Sigma, F1804 and Millipore, 12-371, respectively) in a final volume of $500 \mu \mathrm{l}$, and incubated at $4{ }^{\circ} \mathrm{C}$ for $2 \mathrm{~h}$. After stringent washes, bound RNA was eluted in FA-M2 elution buffer $[50 \mathrm{mM}$ Tris- $\mathrm{HCl}$ (pH 7.5), $10 \mathrm{mM}$ EDTA, $1 \%$ SDS, and $40 \mathrm{U} / \mathrm{ml}$ RNasin] by incubation at $37^{\circ} \mathrm{C}$ for $20 \mathrm{~min}$ with agitation. Eluted RNA and input samples were treated with proteinase $\mathrm{K}$ and decrosslinked at $65^{\circ} \mathrm{C}$ for $2 \mathrm{~h}$. RNA was purified using an RNeasy MiniElute Cleanup Kit (QIAGEN, 74204). cDNA was prepared by reverse transcription using random hexamers, and quantified using a CFX96 Real-Time System (Bio-Rad, C1000 Thermal Cycler)

In vitro RNA-pulldown assay. GAL1 RNA was prepared by in vitro transcription using a TranscriptAid T7 High Yield Transcription Kit (Thermo, K0441). The pulldown mix was prepared in $500 \mu \mathrm{l}$ in vitro pulldown buffer $[40 \mathrm{mM}$ Tris- $\mathrm{HCl}$ (pH 8.0), $150 \mathrm{mM} \mathrm{NaCl}, 0.5 \mathrm{mM} \mathrm{MgAc}, 1 \mathrm{mM}$ DTT, $0.01 \%$ NP40, 5\% glycerol, $0.5 \%$ BSA, $100 \mu \mathrm{g} / \mathrm{ml}$ yeast tRNA, $0.1 \mathrm{U} / \mu \mathrm{R}$ Rasin and protease inhibitors] and contained $1 \mu \mathrm{g}$ target protein, $500 \mathrm{ng}$ in vitro-transcribed RNA, Dynabeads Protein A (Invitrogen, 10001D) and $2.5 \mu$ g antibody (anti-MBP, in-house, 1:3000). The pulldown mix was incubated at $25^{\circ} \mathrm{C}$ for $2 \mathrm{~h}$ and washed five times with $1 \mathrm{ml}$ in vitro pulldown buffer. Washed beads were resuspended in $100 \mu \mathrm{l}$ in vitro pulldown buffer, and $10 \mu \mathrm{l}$ was collected for Western blotting analysis. Bound RNA was purified by PCIAA treatment and the ethanol-down method. cDNA was prepared by reverse transcription using random hexamers, and quantified using a CFX96 Real-Time System (Bio-Rad, C1000 Thermal Cycler).

RNA electrophoretic mobility shift assay. GAL1 RNA was prepared using a TranscriptAid T7 High Yield Transcription kit (K0441, Thermo Scientific) and biotinylated using a Pierce RNA 3' End Biotinylation kit (20160, Thermo Scientific) according to the manufacturer's protocol. Gel-purified biotinylated GAL1 RNA was used for RNA-EMSA. The indicated amount of MBP alone or MBPSgf73p was incubated with $10 \mathrm{nM}$ of biotinylated GAL1 RNA in binding buffer ( 50 $\mathrm{mM}$ Tris- $\mathrm{HCl}$ (pH 7.5), $100 \mathrm{mM} \mathrm{NaCl}, 10 \mathrm{mM} \beta$-mercaptoethanol, $5 \%$ glycerol) for $40 \mathrm{~min}$ at room temperature with gentle agitation. RNA-protein complexes were immobilized on 5\% native gel and transferred to an Amersham Hybond $+\mathrm{N}$ membrane (RPN303B, GE Healthcare). After a brief UV crosslinking, signals were visualized using a Chemiluminescent Nucleic Acid Detection Module (89880, Thermo Scientific) according to the manufacturer's protocol.

\section{Data availability}

All sequencing data that support the findings of this study have been deposited in the National Center for Biotechnology Information Gene Expression Omnibus (GEO; http:// www.ncbi.nlm.nih.gov/geo/) and are accessible through the GEO Series accession number GSE116228. All other relevant data are available from the corresponding author upon request.

Received: 31 August 2018 Accepted: 7 May 2019

Published online: 05 June 2019

\section{References}

1. Chavez, S. et al. A protein complex containing Tho2, Hpr1, Mft1 and a novel protein, Thp2, connects transcription elongation with mitotic recombination in Saccharomyces cerevisiae. EMBO J. 19, 5824-5834 (2000).

2. Strasser, K. et al. TREX is a conserved complex coupling transcription with messenger RNA export. Nature 417, 304-308 (2002).

3. Stutz, F. et al. REF, an evolutionary conserved family of hnRNP-like proteins, interacts with TAP/Mex67p and participates in mRNA nuclear export. RNA 6, 638-650 (2000).

4. Zenklusen, D., Vinciguerra, P., Strahm, Y. \& Stutz, F. The yeast hnRNP-Like proteins Yralp and Yra2p participate in mRNA export through interaction with Mex67p. Mol. Cell Biol. 21, 4219-4232 (2001).

5. Segref, A. et al. Mex67p, a novel factor for nuclear mRNA export, binds to both $\operatorname{poly}(\mathrm{A})+\mathrm{RNA}$ and nuclear pores. EMBO J. 16, 3256-3271 (1997)

6. Fischer, T. et al. The mRNA export machinery requires the novel Sac3pThplp complex to dock at the nucleoplasmic entrance of the nuclear pores. EMBO J. 21, 5843-5852 (2002).
7. Mitchell, P., Petfalski, E., Shevchenko, A., Mann, M. \& Tollervey, D. The exosome: a conserved eukaryotic RNA processing complex containing multiple $3^{\prime}->5^{\prime}$ exoribonucleases. Cell 91, 457-466 (1997).

8. Hilleren, P., McCarthy, T., Rosbash, M., Parker, R. \& Jensen, T. H. Quality control of mRNA $3^{\prime}$-end processing is linked to the nuclear exosome. Nature 413, 538-542 (2001).

9. Iglesias, N. et al. Ubiquitin-mediated mRNP dynamics and surveillance prior to budding yeast mRNA export. Genes Dev. 24, 1927-1938 (2010).

10. Lim, S., Kwak, J., Kim, M. \& Lee, D. Separation of a functional deubiquitylating module from the SAGA complex by the proteasome regulatory particle. Nat. Commun. 4, 2641 (2013).

11. Strasser, K. \& Hurt, E. Yralp, a conserved nuclear RNA-binding protein, interacts directly with Mex67p and is required for mRNA export. EMBO J. 19, 410-420 (2000).

12. Rodriguez-Navarro, S. et al. Sus1, a functional component of the SAGA histone acetylase complex and the nuclear pore-associated mRNA export machinery. Cell 116, 75-86 (2004).

13. Iglesias, N. \& Stutz, F. Regulation of mRNP dynamics along the export pathway. FEBS Lett. 582, 1987-1996 (2008).

14. Pascual-Garcia, P. et al. Sus1 is recruited to coding regions and functions during transcription elongation in association with SAGA and TREX2. Genes Dev. 22, 2811-2822 (2008).

15. Kohler, A., Schneider, M., Cabal, G. G., Nehrbass, U. \& Hurt, E. Yeast Ataxin7 links histone deubiquitination with gene gating and mRNA export. Nat. Cell Biol. 10, 707-715 (2008).

16. Johnson, S. A., Cubberley, G. \& Bentley, D. L. Cotranscriptional recruitment of the mRNA export factor Yral by direct interaction with the $3^{\prime}$ end processing factor Pcf11. Mol. Cell 33, 215-226 (2009).

17. Amrani, N. et al. PCF11 encodes a third protein component of yeast cleavage and polyadenylation factor I. Mol. Cell Biol. 17, 1102-1109 (1997).

18. Collins, S. R. et al. Functional dissection of protein complexes involved in yeast chromosome biology using a genetic interaction map. Nature 446, 806-810 (2007)

19. Zenklusen, D., Vinciguerra, P., Wyss, J. C. \& Stutz, F. Stable mRNP formation and export require cotranscriptional recruitment of the mRNA export factors Yralp and Sub2p by Hpr1p. Mol. Cell Biol. 22, 8241-8253 (2002).

20. Canavan, R. \& Bond, U. Deletion of the nuclear exosome component RRP6 leads to continued accumulation of the histone mRNA HTB1 in S-phase of the cell cycle in Saccharomyces cerevisiae. Nucleic Acids Res. 35, 6268-6279 (2007).

21. Babour, A. et al. The chromatin remodeler ISW1 is a quality control factor that surveys nuclear mRNP biogenesis. Cell 167, 1201-1214 e1215 (2016).

22. Torchet, C. et al. Processing of $3^{\prime}$-extended read-through transcripts by the exosome can generate functional mRNAs. Mol. Cell 9, 1285-1296 (2002).

23. Jensen, T. H. et al. Modulation of transcription affects mRNP quality. Mol. Cell 16, 235-244 (2004).

24. Haruki, H., Nishikawa, J. \& Laemmli, U. K. The anchor-away technique: rapid, conditional establishment of yeast mutant phenotypes. Mol. Cell 31 , 925-932 (2008)

25. Heinz, S. et al. Simple combinations of lineage-determining transcription factors prime cis-regulatory elements required for macrophage and B cell identities. Mol. Cell 38, 576-589 (2010).

26. Baptista, T. et al. SAGA is a general cofactor for RNA Polymerase II transcription. Mol. Cell 68, 130-143 (2017).

27. Jeronimo, C. \& Robert, F. Kin 28 regulates the transient association of mediator with core promoters. Nat. Struct. Mol. Biol. 21, 449-455 (2014).

28. Huisinga, K. L. \& Pugh, B. F. A genome-wide housekeeping role for TFIID and a highly regulated stress-related role for SAGA in Saccharomyces cerevisiae. Mol. Cell 13, 573-585 (2004).

29. Lee, T. I. et al. Redundant roles for the TFIID and SAGA complexes in global transcription. Nature 405, 701-704 (2000)

30. Bonnet, J. et al. The SAGA coactivator complex acts on the whole transcribed genome and is required for RNA polymerase II transcription. Genes Dev. 28, 1999-2012 (2014)

31. Johnson, S. A., Kim, H., Erickson, B. \& Bentley, D. L. The export factor Yra1 modulates mRNA $3^{\prime}$ end processing. Nat. Struct. Mol. Biol. 18, 1164-1171 (2011)

32. Gavalda, S., Santos-Pereira, J. M., Garcia-Rubio, M. L., Luna, R. \& Aguilera, A. Excess of Yral RNA-binding factor causes transcription-dependent genome instability, replication impairment and telomere shortening. PLoS Genet. 12, e1005966 (2016).

33. Meinel, D. M. et al. Recruitment of TREX to the transcription machinery by its direct binding to the phospho-CTD of RNA polymerase II. PLoS Genet. 9, e1003914 (2013).

34. Hurt, E. et al. Mex67p mediates nuclear export of a variety of RNA polymerase II transcripts. J. Biol. Chem. 275, 8361-8368 (2000)

35. Solis, E. J. et al. Defining the essential function of yeast Hsfl reveals a compact transcriptional program for maintaining eukaryotic proteostasis. Mol. Cell 63, 60-71 (2016) 
36. Yamamoto, A., Ueda, J., Yamamoto, N., Hashikawa, N. \& Sakurai, H. Role of heat shock transcription factor in Saccharomyces cerevisiae oxidative stress response. Eukaryot. Cell 6, 1373-1379 (2007).

37. Kaganovich, D., Kopito, R. \& Frydman, J. Misfolded proteins partition between two distinct quality control compartments. Nature 454, 1088-1095 (2008).

38. Escusa-Toret, S., Vonk, W. I. \& Frydman, J. Spatial sequestration of misfolded proteins by a dynamic chaperone pathway enhances cellular fitness during stress. Nat. Cell Biol. 15, 1231-1243 (2013).

39. Ghislain, M., Udvardy, A. \& Mann, C. S. cerevisiae 26 S protease mutants arrest cell division in G2/metaphase. Nature 366, 358-362 (1993).

40. Zander, G. et al. mRNA quality control is bypassed for immediate export of stress-responsive transcripts. Nature 540, 593-596 (2016).

41. Grant, P. A. et al. A subset of TAF(II)s are integral components of the SAGA complex required for nucleosome acetylation and transcriptional stimulation. Cell 94, 45-53 (1998).

42. Henry, K. W. et al. Transcriptional activation via sequential histone $\mathrm{H} 2 \mathrm{~B}$ ubiquitylation and deubiquitylation, mediated by SAGA-associated Ubp8. Genes Dev. 17, 2648-2663 (2003).

43. Lee, D. et al. The proteasome regulatory particle alters the SAGA coactivator to enhance its interactions with transcriptional activators. Cell 123, 423-436 (2005).

44. Ferdous, A., Gonzalez, F., Sun, L., Kodadek, T. \& Johnston, S. A. The 19S regulatory particle of the proteasome is required for efficient transcription elongation by RNA polymerase II. Mol. Cell 7, 981-991 (2001).

45. Sun, L., Johnston, S. A. \& Kodadek, T. Physical association of the APIS complex and general transcription factors. Biochem. Biophys. Res. Commun. 296, 991-999 (2002).

46. Feder, M. E. \& Hofmann, G. E. Heat-shock proteins, molecular chaperones, and the stress response: evolutionary and ecological physiology. Annu. Rev. Physiol. 61, 243-282 (1999).

47. Zid, B. M. \& O'Shea, E. K. Promoter sequences direct cytoplasmic localization and translation of mRNAs during starvation in yeast. Nature 514, 117-121 (2014).

48. De Robichon-Szulmajster, H. Induction of enzymes of the galactose pathway in mutants of Saccharomyces cerevisiae. Science 127, 28-29 (1958).

49. Longtine, M. S. et al. Additional modules for versatile and economical PCRbased gene deletion and modification in Saccharomyces cerevisiae. Yeast 14, 953-961 (1998).

50. Schneider, C. A., Rasband, W. S. \& Eliceiri, K. W. NIH Image to ImageJ: 25 years of image analysis. Nat. Methods 9, 671-675 (2012).

51. Langmead, B., Trapnell, C., Pop, M. \& Salzberg, S. L. Ultrafast and memoryefficient alignment of short DNA sequences to the human genome. Genome Biol. 10, R25 (2009).

52. Li, H. et al. The sequence Alignment/Map format and SAMtools. Bioinformatics 25, 2078-2079 (2009).

53. Ramirez, F. et al. deepTools2: a next generation web server for deepsequencing data analysis. Nucleic Acids Res. 44, W160-W165 (2016)

\section{Acknowledgements}

We thank Katja Sträßer for providing the constructs for the YRA1 and yra1-1 strains. This work was supported by the National Research Foundation of Korea Grant funded by the Ministry of Science and ICT (MSIT) (2018R1A5A1024261, SRC), the Collaborative Genome Program for Fostering New Post-Genome Industry of the National Research Foundation (NRF) funded by the Ministry of Science and ICT (MSIT) (2018M3C9A6065070) and Global Ph.D. Fellowship (2014H1A2A1020223) funded by the National Research Foundation (NRF).

\section{Author contributions}

Conceptualization: M.K., Y.C., and D.L. Investigation: M.K., H.K., and D.L. Writing, review and editing: M.K., Y.C., and D.L. Supervision: D.L.

\section{Additional information}

Supplementary Information accompanies this paper at https://doi.org/10.1038/s41467019-10350-6.

Competing interests: The authors declare no competing interests.

Reprints and permission information is available online at http://npg.nature.com/ reprintsandpermissions/

Journal peer review information: Nature Communications thanks the anonymous reviewer(s) for their contribution to the peer review of this work

Publisher's note: Springer Nature remains neutral with regard to jurisdictional claims in published maps and institutional affiliations.

cc (i) Open Access This article is licensed under a Creative Commons Attribution 4.0 International License, which permits use, sharing, adaptation, distribution and reproduction in any medium or format, as long as you give appropriate credit to the original author(s) and the source, provide a link to the Creative Commons license, and indicate if changes were made. The images or other third party material in this article are included in the article's Creative Commons license, unless indicated otherwise in a credit line to the material. If material is not included in the article's Creative Commons license and your intended use is not permitted by statutory regulation or exceeds the permitted use, you will need to obtain permission directly from the copyright holder. To view a copy of this license, visit http://creativecommons.org/ licenses/by/4.0/

(C) The Author(s) 2019 